\title{
Results of the Eruptive Column Model Inter-comparison Study
}

A. Costa (1,2), Y.J. Suzuki (2); M. Cerminara (3); B.J. Devenish (4); T. Esposti Ongaro (3); M. Herzog (5), A.R. Van Eaton (6), L.C. Denby (5); M. Bursik (7); M. de' Michieli Vitturi (3), S. Engwell (3), A. Neri (3), S. Barsotti (3,8); A. Folch (9), G. Macedonio (10); F. Girault (11), G. Carazzo (11), S. Tait (11), E. Kaminski (11); L.G. Mastin (6); M.J. Woodhouse (12), J.C. Phillips (12), A.J. Hogg (13); W. Degruyter (14), C. Bonadonna (15)

1- Istituto Nazionale di Geofisica e Vulcanologia, Bologna, Italy

2- Earthquake Research Institute, The University of Tokyo, Japan

3- Istituto Nazionale di Geofisica e Vulcanologia, Pisa, Italy

4- Met Office, Exeter, UK

5- Department of Geography, University of Cambridge, UK

6- U.S. Geological Survey, Cascades Volcano Observatory, USA

7- Department of Geology, University at Buffalo, USA

8- Icelandic Meteorological Office, Iceland

9- Barcelona Supercomputing Center, Barcelona, Spain

10- Istituto Nazionale di Geofisica e Vulcanologia, Naples, Italy

11- IPG Paris and Université Paris-Diderot, Paris, France

12- School of Earth Sciences, University of Bristol, UK

13- School of Mathematics, University of Bristol, UK

14- School of Earth and Atmospheric Sciences, Georgia Tech, USA

15- Department of Earth Sciences, University of Geneva, Switzerland 


\section{Abstract}

This study compares and evaluates one-dimensional (1D) and threedimensional (3D) numerical models of volcanic eruption columns in a set of different inter-comparison exercises. The exercises were designed as a blind test in which a set of common input parameters was given for two reference eruptions, representing a strong and a weak eruption column under different meteorological conditions. Comparing the results of the different models allows us to evaluate their capabilities and target areas for future improvement. Despite their different formulations, the 1D and 3D models provide reasonably consistent predictions of some of the key global descriptors of the volcanic plumes. Variability in plume height, estimated from the standard deviation of model predictions, is within $\sim 20 \%$ for the weak plume and $\sim 10 \%$ for the strong plume. Predictions of neutral buoyancy level are also in reasonably good agreement among the different models, with a standard deviation ranging from 9 to $19 \%$ (the latter for the weak plume in a windy atmosphere). Overall, these discrepancies are in the range of observational uncertainty of column height. However, there are important differences amongst models in terms of local properties along the plume axis, particularly for the strong plume. Our analysis suggests that the simplified treatment of entrainment in 1D models is adequate to resolve the general behaviour of the weak plume. However, it is inadequate to capture complex features of the strong plume, such as large vortices, partial column collapse, or gravitational fountaining that strongly enhance entrainment in the lower atmosphere. We conclude that there is a need to more accurately quantify entrainment rates, improve the representation of plume radius, and incorporate the effects of column instability in future versions of 1D volcanic plume models. 
Keywords: Explosive volcanism; Eruptive plumes dynamics; Fluid dynamic models; Model inter-comparison; Eruption source parameters 


\section{Introduction}

To improve our understanding of the physics of volcanic plumes and their interaction with the atmosphere, increasingly sophisticated numerical models of eruptive columns have been developed by a growing number of research groups. These models are different in their design and scope, but all have the fundamental goal of characterizing the dynamics of volcanic plume formation and ultimately providing estimates of source conditions. Descriptions of volcanic columns (or plumes, we use the terms interchangeably in this paper) are important for hazard mitigation because they can be used in models that forecast the dispersion of ash and hazardous gases in the atmosphere. The accuracy of tephra dispersal forecasts is strongly dependent on the source term, which describes both the mass eruption rate of volcanic emissions and their initial vertical distribution in the atmosphere. However, until now there has not been a systematic effort to compare how these source terms are derived. For this study, we have brought together 13 different models to perform a set of simulations using the same input parameters, so that results can be meaningfully compared and evaluated. The motivation is twofold: (1) to provide a conceptual overview of what the various models can accomplish, and (2) to target specific areas for further exploration by the research community as a whole.

\section{Background on volcanic eruption column models}

Numerical models of explosive volcanic eruptions range in complexity from those requiring a computer cluster, to those requiring only seconds on a laptop or web interface. The models used in this study fall into two main categories: onedimensional (1D) integral models, based on different applications of the mathematical description of turbulent buoyant plumes by Morton et al. (1956), and three- 
dimensional (3D) models, designed to resolve the detailed turbulence structure of volcanic plumes. Simpler $\left(0^{\text {th }}\right.$ order $)$ empirical scaling relationships also exist. As summarized in Table 1, this study brings together a selection from each of these categories, including 13 different 1D and 3D models. In the following sections, we provide a brief background and description for each.

\subsection{Empirical scaling relationships $\left(0^{\text {th }}\right.$ order $)$}

These are empirical scaling relationships between plume height and mass eruption rate (MER) based on observed eruptions, some of which include a simplified description of the atmosphere (e.g., Mastin et al., 2009; Degruyter and Bonadonna 2012; Woodhouse et al. 2013; Carazzo et al. 2014). These relationship and the values used in them are presented in Table 2.

The relationship proposed by Mastin et al. (2009) is calibrated on a dataset of historical eruptions and the wind condition is not described explicitly, although the use of observational data means that the effects of wind are averaged into the calibration.

In contrast, the relationships derived by Degruyter and Bonadonna (2012), Woodhouse et al. (2013), and Carazzo et al. (2014) explicitly account for the effects of wind. The scarcity of observations with corresponding meteorological measurements means that the Degruyter and Bonadonna (2012) and Woodhouse et al. (2013) relationships are calibrated using 1D plume model computations, which have been shown to describe the observational data (Woodhouse et al., 2013). The relationship of Degruyter and Bonadonna (2012) includes the measured atmospheric temperature and wind profile, source thermodynamic properties, and values of the entrainment coefficients. Woodhouse et al. (this issue) have explicitly included the 
measured atmospheric buoyancy frequency and source thermodynamic properties (combining equations 28 and 29 of Woodhouse et al. (2013)), and have inverted the expression of Woodhouse et al. (2013) to give the source mass flux as a function of plume height. Carazzo et al. (2014) have used analogue experiments of strong and weak plumes to build relations that take the wind velocity into account.

The variability and uncertainties of the empirical relationships reflect those of field observations, results of 1D models, and experimental results, on which these relationships are based.

\subsection{One-dimensional integral models}

1D volcanic plume models have their origins in the work of Wilson (1976) who applied the mathematical description of turbulent buoyant plumes developed by Morton, Taylor, and Turner (1956), hereafter referred to as Buoyant Plume Theory (BPT), to explosive volcanic eruptions. Morton et al. (1956) envisioned the eruption column as a time-averaged Boussinesq plume, in which density differences are negligible, except where they give rise to a buoyancy force. The characteristic timescale of the plume is considered to be longer than that of turbulent motion, thereby removing the need to describe the turbulence in detail. Within this framework, Morton et al. (1956) described turbulent mixing as a horizontal inflow of ambient air into the plume, occurring at a rate proportional to the mean vertical velocity of the plume. Furthermore, the ratio of inward horizontal to upward vertical velocity is assumed to be constant at all heights. This assumption allows closure of the evolution equations for the mass (equivalently, volume for an incompressible fluid), momentum, and buoyancy fluxes. BPT assumes self-similarity of the radial profile of the time-averaged plume properties such as the axial velocity and bulk density. 
Existing models use a range of different profiles, with some assuming a top-hat form, and others a Gaussian (e.g. Davidson, 1986).

Despite their simplicity, 1D models have been remarkably successful at describing buoyant plumes (e.g., List, 1982; Turner, 1986; Linden, 2000; Hunt, 2010) and continue to be the subject of much research. They have been extended to include the effects of a cross-flow (e.g., Priestley, 1956; Hewett et al., 1971; Briggs, 1975; 1984; Weil, 1988) and moisture (e.g., Morton, 1957; Weil, 1974).

The application of BPT to volcanic plumes requires a relaxation of the Boussinesq assumption as a result of the large density differences between the plume and the environment, large temperature differences, and the large accelerations that occur in volcanic plumes. In addition, models such as those developed by Sparks (1986) who generalized results of Wilson (1976), considered the effect of different phases (ash, gas) on the bulk properties of the plume, and using some of the thermodynamics of compressible gas flows.

The basic equations used in most of the 1D models used in the present intercomparison study are based on Woods (1988) who re-formulated the model from the starting point on the basis of the conservation laws. Woods (1988) assumes pressure equal to ambient pressure at a given elevation and gas properties governed by the ideal gas relations, and to consist of a homogeneous mixture of all phases (air, volcanic gas, and pyroclasts), with perfect thermal and mechanical equilibrium among all phases. The bulk properties of the mixture are weighted sums of each phase. Further development of volcanic plume models has incorporated additional processes, such as effects of moisture (e.g., Woods, 1993; Koyaguchi and Woods, 1996; Mastin, 2007) and ambient wind (e.g., Bursik 2001). 
To account for weak volcanic plumes that are bent over by the wind, the classic BPT model requires a different parameterization of entrainment. For a plume that is neither strongly bent-over nor rising vertically, it is commonplace to assume, on a purely empirical basis, that there are two mechanisms of turbulent mixing in a crossflow: one due to velocity differences parallel to the plume axis and the other normal to the plume axis. The two mechanisms are assumed to be additive, and entrainment rate may be defined by

$$
E=2 \pi R \rho_{a}\left(\alpha \Delta u_{s}+\beta \Delta u_{n}\right)
$$

where $R$ is the plume radius, $\rho_{a}$ is the ambient density, and $\Delta u_{s}$ and $\Delta u_{n}$ are the components of the relative velocity parallel and normal to the plume axis, respectively, and $\alpha$ and $\beta$ are referred to as entrainment coefficients. In a windless situation, the plume rises vertically so that $\Delta u_{n} \equiv 0$ and $\Delta u_{s}$ is precisely the vertical velocity of the plume, and the entrainment formulation (1) reduces to the original entrainment parameterization of Morton et al. (1956). The entrainment coefficient for the vertically rising plume, here denoted by $\alpha$, is relatively well constrained by experiments, with reported values in the range of $0.08-0.15$, depending in part on whether a Gaussian or top-hat velocity profile is used (e.g., Briggs, 1984; Papanicolaou and List, 1988). In the literature, this parameter has been considered either constant (Morton et al., 1956), or a function of a dimensionless combination of the plume variables such as density (through a local Richardson number) or concentration (e.g., Priestley and Ball, 1956; Richou, 1961; Kaminski et al., 2005; Suzuki and Koyaguchi, 2010). The entrainment coefficient that describes the effect of wind, here denoted by $\beta$, is less well constrained experimentally. It is generally thought to range from about 0.4 to 0.9 (e.g., Hewett, 1971; Briggs, 1975; 1984; Fay et al., 1969; Hoult et al., 1969; Hoult and Weil, 1972; Davidson 1989; Huq and Stewart, 
1996; Devenish et al., 2010; Contini et al., 2011). As we will see in the following sections, different models adopt different values of entrainment coefficients based on their specific formulation or calibration against well-documented case studies.

The following 1D integral models were included in this inter-comparison exercise:

1. Puffin (Bursik, 2001; Pouget et al., this issue):

Puffin is a one-dimensional, steady state, non-Boussinesq plume model. Puffin describes plumes that entrain mass, momentum, and energy from the still air and wind (Hewett et al, 1971; Woods, 1988). It is a trajectory model, based on applying the equations of motion in a plume-centred coordinate system. As originally presented, and as used in the present contribution, the model tracks plume growth into the downwind or umbrella cloud phase, and accounts for particle fallout and particle reentrainment following Bursik et al. (1992) and Ernst et al. (1996).

Inputs include total grain-size distribution, either typical of different eruption types or specified to characterize a particular eruption, eruption temperature, magmatic volatile content, vent radius and initial eruption mixture speed. The atmospheric profiles (e.g. wind speed, temperature, humidity) can be specified analytically, or taken from radiosonde data or numerical weather prediction models. Grain-size distribution is characterized by a mean and standard deviation, and assumed to be lognormal (modified to bi-lognormal for this study). Radial and crosswind air entrainment were originally parameterized using the two entrainment coefficients $\alpha$ and $\beta$ respectively, set to the default values $\alpha=0.15$ and $\beta=1.0$. Note that these are at the very high end of the values explored for either parameter in the 1D models and, therefore, the effects of high entrainment are pronounced in the Puffin results. 
The model has been updated to include the effects of water phase changes, and variable parameter values. Prognostic equations for mass flux of gas and separate particle phases, radial and tangential momentum flux and enthalpy flux are solved with a fourth order Runge-Kutta routine. Primitive and state variables are then solved with diagnostic equations. More detailed information about this model and its current state of development, including sensitivity analysis to parameter values and initial conditions can be found in Pouget et al. (this issue).

2. Degruyter (Degruyter and Bonadonna, 2012):

This model is based on the one-dimensional, steady state plume model of Woods (1988), with the addition of (a) wind following Hoult et al. (1969) and Bursik (2001), and (b) humidity based on Glaze and Baloga (1996) and Glaze et al. (1997). The model does not account for particle fallout but does consider effects of humidity and phase changes of water. Radial and cross-wind air entrainment are parameterized using equation (1) with constant values for the radial and wind entrainment coefficients. The default values are $\alpha=0.1$ and $\beta=0.5$, following Devenish (2010). More detailed information about this model can be found in Degruyter and Bonadonna (2012, 2013).

3. PlumeMoM (de' Michieli Vitturi et al., 2015; this issue):

PlumeMoM is a volcanic plume model that accounts for the effect of wind, which results in the bending of the plume trajectory and increases entrainment of ambient air. The model solves the equations for the conservation of mass, momentum, energy, and the variation of heat capacity and mixture gas constant. In contrast to previous works, in which the pyroclasts are partitioned into a finite number of classes, in 
PlumeMoM the method of moments is used to describe a continuous size distribution of one or more families of particles.

The model accounts for particle fallout but does not consider the effects of humidity, nor phase changes of water. Radial and cross-wind air entrainment are parameterized using the two entrainment coefficients $\alpha$ and $\beta$ respectively, set to the default values of $\alpha=0.09$ and $\beta=0.6$. More detailed information about this model can be found in de' Michieli Vitturi et al. (this issue).

\section{Devenish (Devenish, 2013):}

This volcanic plume model includes both the effects of moisture (water vapour and liquid water only; no ice) and the ambient wind. It is similar to those developed by, for example, Woods (1988) and Mastin (2007). The model can be applied iteratively to refine an initial estimate of the mass flux for a given target height. Note that in this case only the source mass flux is allowed to vary - all other input source parameters are kept fixed.

The model does not distinguish between pyroclasts in the fine and coarse classes; only one size class is used. It does not account for particle fallout. The model includes the effects of humidity and phase changes of water. Radial and cross-wind air entrainment are parameterized using the two entrainment coefficients $\alpha$ and $\beta$ respectively, set to the default values of $\alpha=0.1$ and $\beta=0.5$. As a further empirical modification, the radial and cross-flow entrainment terms in equation (1) are raised to an exponent that controls the relative importance of the two terms in parentheses. More detailed information about this model can be found in Devenish (2013; this issue). 
5. FPlume (Folch et al. 2015; Macedonio et al., this issue):

FPume model is based on the solution of the equations for the conservation of mass, momentum, and energy in terms of cross-section averaged variables (Woods, 1988; Bursik, 2001). The model accounts for particle fallout, particle re-entrainment, entrainment of ambient moisture, and phase changes of water. The model also considers for the effects of the wind, which results in the bending over of the plume and increases the entrainment of ambient air (e.g., Bursik, 2001). FPlume also considers wet aggregation phenomena based on Costa et al. (2010), thereby modifying the particle grain-size distribution. The region above the NBL is described using a semi-empirical approach, assuming pseudo-gas relationships with pressure assumed equal to the atmospheric pressure at each level, and temperature decrease with the altitude due to the adiabatic cooling (see Folch et al., 2016). Radial and cross-wind air entrainment are parameterized using either two user defined coefficients $\alpha$ and $\beta$ respectively, or through two entrainment functions based on the local Richardson number and average wind intensity. The model outputs are also used to produce input for the Fall3d tephra transport model (Costa et al., 2006; Folch et al., 2009). More detailed information about this model can be found in Folch et al. (2015) and Macedonio et al. (this issue).

\section{Paris Plume Model (PPM) (Girault et al., 2014; this issue):}

PPM is a volcanic plume model that uses the formulation of Woods (1988), refined by Bursik (2001), for the conservation laws of mass, axial and radial momentum, and energy fluxes for a particle-laden turbulent jet rising in a windy atmosphere. The PPM model adopts a top-hat entrainment coefficient $\alpha$ that depends on the local buoyancy of the column relative to the ambient, similarly to Kaminski et 
al. (2005) and Carazzo et al. (2006, 2008). The rate of turbulent entrainment of ambient air into the plume is parameterized as in Hewett et al. (1971) where the entrainment coefficient due to wind is set to a constant $\beta=0.5$ (Devenish et al., 2010).

The PPM model accounts for particle fallout, but does not consider the effects of particle re-entrainment, humidity or phase changes of water. The mass loss of particles follows the description of Woods and Bursik (1991) and Ernst et al. (1996), adopting the particle settling velocities given in Bonadonna et al. (1998). The model assumes freely decompressing jet conditions at the vent, according to which the plume velocity at the vent is related to the free exsolved gas content as suggested by Woods and Bower (1995). More detailed information about this model can be found in Girault et al. (2014; this issue).

\section{Plumeria (Mastin, 2007; 2014):}

Plumeria is a volcanic plume model based on the formulation of Woods (1988) modified to account for a cross-wind (e.g., Bursik, 2001). Radial and cross-wind air entrainment coefficients are set to the default values of $\alpha=0.09$ and $\beta=0.5$.

The thermodynamic phase relations for water are calculated as follows: above the freezing temperature, the mass fractions of liquid water and water vapour are assumed to be at equilibrium values at a given pressure and temperature. Below freezing, as constrained by observations of ice-coated ash (Durant and Shaw, 2005; Seifert et al., 2011), ice is assumed to co-exist with liquid water over a temperature range from -7.5 to $-15^{\circ} \mathrm{C}$, with the mass fraction of liquid and ice varying linearly over this range.

To be consistent with other models in this comparison, the plume height was taken to be the maximum height reached by the plume centreline (see complications in reporting plume height discussed by Mastin, 2014). Plumeria does not account for 
particle fallout. More detailed information about this model can be found in Mastin (2014).

8. PlumeRise (Woodhouse et al. 2013; this issue):

PlumeRise is a volcanic plume model that adopts the thermodynamic description proposed by Woods (1988). PlumeRise allows the source and atmospheric controls on the rise of volcanic plumes to be assessed, and includes a description of the thermodynamics of phase changes of water. The model also accounts for the effects of cross-wind on the rise of plumes through enhanced mixing of ambient air. Furthermore, the entrained atmospheric air carries horizontal momentum and the plume therefore acquires this momentum and is bent over by the wind. PlumeRise models the effect of a cross-wind on plume ascent using the entrainment formulation of Hewett et al. (1971). Radial and cross-wind air entrainment are parameterized using the two entrainment coefficients $\alpha$ and $\beta$ respectively, set to the default values of $\alpha=0.09$ and $\beta=0.9$.

The model is intended to give rapid estimation of the rise height of wind-blown volcanic plumes, or to infer the mass eruption rate from observations of the plume height, and therefore is mainly applicable to eruption columns that become buoyant. PlumeRise assumes that particle fallout has a secondary influence on plume dynamics and therefore does not describe particle fallout. However, the effects of humidity and phase changes of water are included in the model. More detailed information about this model can be found in Woodhouse et al. (this issue).

9. Dusty-1D (Cerminara, 2015): 
Dusty-1D uses an extension of the plume model formulation of Woods (1988) for the conservation laws of mass, momentum, and energy fluxes in the volcanic context. The model does not account for particle fallout but it considers the dependence of the entrainment coefficient on the density contrast in the jet region near the vent (e.g., Richou, 1961; Woods, 1988). Radial entrainment is parameterized using the entrainment coefficient $\alpha$, set to the default value of $\alpha=0.1$. The effects of wind are not considered. More detailed information about this model can be found in Cerminara and Esposti Ongaro (this issue).

\subsection{Three-dimensional plume models}

Three-dimensional (3D) plume models are based on the time-dependent solution of the Navier-Stokes equations for the conservation of mass, momentum, and energy/enthalpy, describing the fluid dynamics of the eruptive mixture and the surrounding atmosphere. The basic information needed to initialize these models is an atmospheric sounding and a description of the flux of volcanic ash and gases into the atmosphere. Simulations then resolve the time-dependent properties of the volcanic plume at each grid cell in a 3D domain. Each model differs in its description of the eruptive mixture, and of the physical and chemical processes that take place (e.g., subgrid turbulence modelling and cloud microphysics). They also follow different approaches to the numerical solution of the model equations. For example, the description of the eruptive mixture may be based on the pseudogas model (e.g., Marble, 1970), which assumes that volcanic particles are in kinetic and thermal equilibrium with the gas phase. Alternatively, different types of non-equilibrium relations can be introduced to describe gravitational settling, kinematic decoupling, and kinetic or thermal disequilibrium, for which multiphase flow models are required. 
They also follow different approaches for the numerical solution of the governing equations.

10. ATHAM (Active Tracer High Resolution Atmospheric Model; Oberhuber et al., 1998):

Originally developed to simulate volcanic eruption plumes, ATHAM is conceptually a non-hydrostatic, atmospheric circulation model that can be used for spatial scales and domains typical of cloud-resolving and LES (Large Eddy Simulation) models. Volcanic plumes are forced by a lower boundary condition for the erupting mixture. In addition to the vent size, the exit velocity, temperature, and composition of the mixture are prescribed as functions of time.

ATHAM has a modular structure. Modules for different physical processes and complexity can be selected as needed for the application under consideration. The dynamical core solves the compressible Euler equations that describe the evolution of the momentum, pressure, and temperature of a gas-particle mixture. Active tracers can occur in any concentrations and impact the density and heat capacity of the mixture. Active tracers can be either compressible, such as water vapour sourced from the eruption or atmosphere, or incompressible, such ash tephra particles, cloud or rain droplets. To account for multiple particle sizes without huge computational cost, the model assumes that particles are in dynamical and thermal equilibrium with the flow field. In ATHAM, dynamical equilibrium means an instantaneous exchange of momentum in the horizontal direction, so that the velocities of the components of the mixture only differ in the vertical. This allows for a representation of gas-particle separation as well as particle sedimentation. Particle properties such as radius and density determine the settling speeds. Thermal equilibrium assumes an instantaneous 
exchange of heat, so that the components in each grid cell have the same temperature (Oberhuber et al., 1998). The sub-grid turbulence closure scheme differentiates between the horizontal and vertical directions and computes turbulence exchange coefficients for each dynamical quantity (Herzog et al., 2003). Cloud microphysical processes include the growth of liquid and ice hydrometeors, such as rain and hail (Herzog et al., 1998; Van Eaton et al., 2012).

11. SK-3D (Suzuki et al., 2005; Suzuki and Koyaguchi, 2009):

SK-3D is a 3D plume model designed to describe the evolution of volcanic columns and umbrella clouds under arbitrary atmospheric conditions. The model simulates the injection of a mixture of solid pyroclasts and volcanic gas (assumed to be water vapour) from a vent above a flat surface into the atmosphere. The momentum and heat exchanges between the solid pyroclasts and gas are assumed to be so rapid that the velocity and temperature are the same for all phases. This assumption is valid when the size of solid pyroclasts is sufficiently small, i.e. $<1 \mathrm{~mm}$ (Woods and Bursik, 1991). Under this assumption, the mixture of solid pyroclasts and volcanic gas is treated as a single gas (i.e., pseudogas or dusty-gas approximation; Marble, 1970) and the separation of solid pyroclasts from the eruption cloud is ignored.

To reproduce the nonlinear variation of the eruption cloud properties with the mixing ratio between the ejected material and the entrained air, the effective gas constant and heat capacity of the mixture are functions of the mixing ratio in the equation of state. The fluid dynamic model solves a set of partial differential equations describing the conservation of mass, momentum, and energy, and a set of constitutive equations describing the thermodynamic state of the mixture of solid 
pyroclasts, volcanic gas, and air. These equations are solved numerically by a general scheme for compressible flow with high spatial resolution. Suzuki et al. (2005) carried out numerical simulations of jets with and without the large eddy simulation (LES), and compared them to investigate the effects of the small-scale structures that cannot be resolved on a given grid. Simulation results showed that when spatial resolution is sufficiently high using a third-order accuracy scheme and a fine grid, the numerical results both with and without LES correctly reproduce the spreading rate of jets observed in experiments, indicating that spatial resolution is the essential factor, and that the subgrid scale models play only a secondary role in reproducing the global features of turbulent mixing and efficiency of entrainment. This can be explained by the fact that the efficiency of entrainment is determined by the kinematic evolution of the largest eddies, and that the major function of the subgrid sizes is only to dissipate the kinetic energy provided by the large eddies. Using this 3D model, the entrainment coefficients of eruption columns under the conditions with and without wind have been estimated (Suzuki and Koyaguchi, 2010; 2015).

More detailed information about this model can be found in Suzuki et al. (2005) and Suzuki and Koyaguchi (2009).

12. ASHEE (Cerminara et al., 2015; Cerminara et al., this issue)

ASHEE (Ash Equilibrium-Eulerian) model is a compressible, multiphase flow model to simulate the three-dimensional dynamics of turbulent volcanic ash plumes. The model describes the eruptive mixture as a polydisperse fluid, composed of different types of gases and particles, treated as interpenetrating Eulerian phases. Solid phases represent the discrete ash classes, in which the total granulometric spectrum is discretized. Particles can differ in size and density. The model is based 
on the turbulent, dispersed multiphase flow theory (Balachandar and Eaton, 2009) for dilute flows, neglecting particle collisions and considering only fine particles (finer than about $1 \mathrm{~mm}$ ). This is a refinement of the pseudogas model, in which the velocity and temperature are the same for all phases (Marble, 1970). The assumptions of the model are physically well-justified in the absence of particle collisions, or for a dilute suspension, in which the volumetric concentration is less than 0.001 (Elghobashi, 1991; 1994). These assumptions are applicable for particles < 1 1mm for which the Stokes number is less than 0.2. It adopts a dynamic LES formalism for compressible flows to model the non-linear coupling between turbulence scales, and the effect of sub-grid turbulence on the large-scale dynamics (e.g., Lesieur, 2005; Nicoud and Ducros, 1999). The effects of wind on the plume are not accounted for. More detailed information about this model can be found in Cerminara et al. (this issue).

13. PDAC (Neri et al., 2003; Esposti Ongaro et al., 2007; Carcano et al., 2013):

PDAC is a non-equilibrium, multiphase flow model for the simulation of the transient, three-dimensional dispersal of volcanic gases and particles ejected from a volcanic vent into the atmosphere. Each phase of the eruptive mixture (gas and pyroclasts of different size and density) is described separately from the others by solving the corresponding mass, momentum, and energy balance equations. The multiphase flow model thus describes kinetic and thermal non-equilibrium interactions between gas and particles, and interphase momentum and energy exchanges among them (Neri et al., 2003). Subgrid scale turbulence is described by a LES approach. The effects of wind on the plume are not accounted for. Model equations are solved by a second-order finite-volume discretization scheme and a pressure-based iterative nonlinear solver suited to compressible multiphase flows. The 
model can be run in parallel on most distributed memory High-Performance Computing architectures. More detailed information can be found in Esposti Ongaro et al. (2007), and Esposti Ongaro and Cerminara (this issue).

\section{Methods of inter-comparison}

Model inter-comparison techniques have been developing over the years in research communities including climate and Earth systems (e.g., Gates et al., 1999; Friedlingstein et al., 2006), and volcanology (e.g., Sahagian, 2005). In our approach, the modelling groups were given minimal direction, aside from the basic model inputs, to ensure that participating groups had the freedom to set up their models as required. Therefore, aspects of the individual modelling choices that are implicit in the models remain within the scope of the comparison (e.g., entrainment coefficients, methods of interpolating atmospheric data onto the model grid, grid resolution). During the exercise, these modelling decisions promoted discussion among participants, some of which are communicated in the analysis presented here, and in the accompanying papers in this volume.

\subsection{Eruption scenarios - Weak vs. strong plume}

For the model inter-comparison, two sets of standard input parameters were provided: one representative of a weak eruption column in a windy atmosphere, and a strong eruption column under low-wind conditions. We refer to these cases as the weak plume and strong plume, respectively, even when the wind effects are ignored for sensitivity studies. Distinctions between strong and weak behaviour have been quantified in different ways (e.g., Sparks et al., 1997, Chapter 11; Degruyter and Bonadonna, 2012; Carazzo et al., 2014). The standard definition is based on the 
dimensionless ratio of the wind speed to the characteristic vertical velocity of the plume. When the average wind speed is much smaller than the typical vertical velocity scale of the plume, we expect the eruption column to rise almost vertically (commonly referred to as a strong plume); otherwise the plume trajectory can be substantially bent over to produce a so-called weak plume. The motivation for providing these two test cases was to compare the models over a wide range of spatial scales and dynamic processes. Although not explicitly specified during the exercise (simulations were done as a blind test), the weak plume scenario was based on the 26 January 2011 Shinmoe-dake eruption, Japan, that produced a plume that reached about 8 km above sea level (Hashimoto et al., 2012; Kozono et al., 2013; Suzuki and Koyaguchi, 2013). The strong plume scenario was based on the climactic phase of the Pinatubo eruption, Philippines, on 15 June 1991, during which the eruption column reached about $39 \mathrm{~km}$ above sea level (Koyaguchi and Tokuno, 1993; Holasek et al., 1996; Costa et al., 2013).

In addition to the volcanic inputs (Table 3), we specified the constants for some of the common parameters required for modelling in Table 4. Meteorological profiles for the two scenarios were also provided (Fig. 1). For the erupted particles, only two size classes were considered, representing coarse ash $\left(\Phi_{c}\right)$ and fine ash $\left(\Phi_{f}\right)$, each comprising 50 wt.\% of the erupted particles (diameters given in $\Phi$-units, where diameter $d=2^{-\Phi} \mathrm{mm}$ ). For models that can deal with multiple size classes, it was recommended to consider a sum of two $\Phi$-Gaussian distributions (with a weight of $50 \%$ ) with modes specified in Table 3 and a standard deviation $\sigma_{\Phi}=1.6 \Phi$-units.

\subsection{Modelling exercises and definitions}


Four modelling exercises were used to simulate the weak and strong plume scenarios described above. These included forward and inverse modelling, with and without the effects of wind. The forward approach used a fixed mass eruption rate (MER) and solved for the final column height. The inverse approach used a fixed column height, varying the MER until the specified height was achieved. We also compared the effects of neglecting the background winds, and accounting for them, both in terms of the bending of the plume trajectory and the additional cross-wind entrainment. The summary of all simulations and corresponding identifiers are given in Table 5. The high computational costs of 3D models precluded the solution of inverse problems, so they carried out the forward solutions only (exercises 1 and 3). The 3D models that do not account for wind only performed exercise 1 .

The simulated volcanic plumes were characterized in terms of global and local parameters. The global (bulk) characteristics of the plume include the calculated MER, maximum plume height, and neutral buoyancy level (NBL). Local parameters include the more detailed profiles of parameters along the plume centerline, such as vertical velocity and mass fraction of entrained air. For the sake of consistency, all models considered the plume height to be the maximum height reached by the plume centreline (see complications in reporting plume height discussed by Mastin, 2014). To compare the local parameters from $1 \mathrm{D}$ and 3D models, a filter, based on a generalization of the method suggested by Kaminski et al. (2005), was applied to all 3D models to furnish the same quantities averaged in a fixed time-window in which the plume is stationary, and over cross-sections orthogonal to the plume axis (Suzuki et al., submitted-a). The procedure to estimate the NBL in the $3 \mathrm{D}$ simulations is described in Suzuki et al. (submitted-a). The following ten variables, as a function of the elevation, $Z$, were requested: 
- $\quad Z$ (height in $\mathrm{m}$ );

- $\quad R$ (plume radius in $\mathrm{m})$;

- $\quad X$-position of plume axis (in $\mathrm{m}$ );

- $\quad Y$-position of plume axis (in m);

- $\quad \rho$ (plume density in $\mathrm{kg} \mathrm{m}^{-3}$ );

- $\quad T$ (plume temperature in ${ }^{\circ} \mathrm{C}$ );

- $\quad V$ (plume velocity in $\mathrm{m} \mathrm{s}^{-1}$ );

- $\quad m_{a}$ (entrained air mass fraction);

- $\quad m_{g}$ (gas mass fraction);

- $\quad m_{p}$ (pyroclasts mass fraction).

\section{Results}

\subsection{Global characteristics - Predicted column heights and MER}

Simulated values of the MER and column height are reported in Tables 6-13 and Figs. 2 and 3. We have also shown corresponding values using the empirical plume height scaling relationships of Mastin et al. (2009), Degruyter and Bonadonna (2012), Woodhouse et al. (2013), and Carazzo et al. (2014).

For simulations with fixed MER, the model results show substantial differences among predicted column heights. The standard deviation among models within a given exercise ranges from $8 \%$ for the strong plume with wind effects, to $27 \%$ for the weak plume with wind (Tables $6,8,10$, and 12). For simulations neglecting wind, the difference between the average plume height given by models and empirical scaling of Mastin et al. (2009) is relatively small, ranging from $\sim 30 \%$ for the strong plume to about $6 \%$ for the weak plume. However, the differences become large when wind is 
taken into account, ranging from $\sim 40 \%$ for the strong plume case to $115 \%$ for the weak plume case. This suggests that, first, a constant wind speed, as included in most empirical relationships, can lead to large differences in predicted column height. The empirical relationships proposed by Carazzo et al. (2014) yield larger differences with the average of the model results ( 7 to $30 \%$ ), in particular for the windy weak plume (80\%). This comparison suggests that the use of a variable entrainment coefficient and a constant wind speed can lead to large differences in predicted height. The algebraic relationships proposed by Degruyter and Bonadonna (2012) and the improved version of Woodhouse et al. (2013) (see Woodhouse et al., this issue), both verified by comparison with 1-D models, are consistently closer to the average of the model results (and generally within the standard deviation). Differences range from less than $9 \%$ for strong plumes with no wind, to about $-8 \%$ for weak plumes with no wind, and only a few percent for strong and weak plume with wind effects.

For the simulations with a fixed column height, there are significant differences among the MERs predicted by the models, with the standard deviation ranging from $46 \%$ for the strong plume without wind, to $96 \%$ for the weak plume with wind. The difference between the average MER of the model results and that given by the empirical relationship proposed by Mastin et al. (2009) is about a 60-70\% for the strong plume cases; a high-MER scenario for which few data constrain the empirical relationship. By contrast, the difference varies considerably for the weak plume cases, from only $-7 \%$ when wind is ignored, to $-96 \%$ for exercises considering wind effects. The empirical relationships proposed by Carazzo et al. (2014) yield larger differences with the average of the model results ( 8 to $63 \%$ ), in particular for the windy weak plume (95\%). 
Similar to the cases with fixed MER, the empirical scaling relationship proposed by Degruyter and Bonadonna (2012) shows a much smaller difference in predicted height with the average of the model results, ranging from about -30 to $10 \%$ for the strong plume cases without and with wind effects, and from about $-20 \%$ to $40 \%$ for the weak plume cases without and with wind effects. Generally the difference is within the standard deviation of the models taken together. For these cases, the improved version of the algebraic relationship of Woodhouse et al. (2013) shows even smaller differences ranging from about $-15 \%$ to $6 \%$.

Among the 1-D models, differences in formulation or in processes included in some models result in little difference in the output. Codes that consider latent heat of water for example (models 2,4,5,7,8,9) do not produce clearly higher plumes in Fig. 2. Nor are plume heights substantially different for codes that consider particle fallout $(1,3,5,6)$, re-entrainment (5), use Richardson-number-based entrainment coefficients $(5,6)$ or add exponential weighting to the radial and cross-flow terms in eq. (1) $(4,7)$. The variations among the 3D models only are described in Suzuki et al (submitted-a).

\subsection{Local characteristics - Variables along the plume centreline}

Figs. 4-11 compare the different plume variables produced for the four modelling exercises.

\subsubsection{Weak plume}

Broadly speaking, there is good agreement amongst $1 \mathrm{D}$ and $3 \mathrm{D}$ models for the weak plume, suggesting that effect of down-flow above the NBL (ignored by 1D models) is not significant. For example, profiles of bulk density and temperature match well amongst the different models in Figs. 5 and 10. Velocity along the plume 
centreline also shows general agreement in the shape of the profile (Fig. 11), although 1D models predict velocities that are somewhat on the higher side compared to 3D. Even the profiles of entrained air mass fraction are consistent (Fig. 4), despite widely varying treatments of turbulence in each model, likely because all the models roughly capture the same large scale structures. The parameter that differs most is plume radius (Fig. 8). In the no-wind scenario, plume radii predicted by $1 \mathrm{D}$ models match those from 3D up to the level of neutral buoyancy. However, all of the 1D models (except \#5) assume that the plume continues spreading monotonically with height, whereas 3D simulations show a more realistic tapering off toward the top. The result is that $1 \mathrm{D}$ models, with respect to $3 \mathrm{D}$ models, significantly overpredict the radius of the upper portion of the plume. Moreover, the 1-D plume heights in Fig. 8 underpredict the maximum plume height by up to a few tens of percent. In the scenario that includes wind effects, this tendency is still visible despite the complex geometry of the wind-bent plume, which spreads at different heights due to changes in wind velocity with height.

\subsubsection{Strong plume}

In contrast to the weak plume, modelled profiles from the strong plume scenarios show much greater variability. The results obtained from 3D models are sensitive to the averaging method used, but these differences are generally smaller than the differences between 1D and 3D models (Suzuki et al., this issue-a).

Bulk density is the only parameter with reasonably good agreement amongst 1D and 3D models (Fig. 5). This is likely because the plume density is comparable to atmospheric density above the jet region. However, the 1D profiles of temperature and velocity are systematically higher than those predicted by 3D models (Figs. 10 
and 11), and entrained air is systematically lower (Fig. 4). This divergence between the two categories of models indicates that the 1D models underestimate the amount of air entrainment into the strong plume simulated here, allowing them to maintain higher temperatures and velocities than their 3D equivalents. For example, there are regions where modelled velocities differ by more than $100 \mathrm{~m} / \mathrm{s}$ (Fig. 11) and temperature differs by $\sim 500{ }^{\circ} \mathrm{C}$, for instance at $10 \mathrm{~km}$ (Fig. 10).

This is a clear example in which entrainment rates assumed by the 1D models are compatible with existing experimental data, yet fail to capture the fundamental behaviour of the volcanic plume. In this case, the $3 \mathrm{D}$ models show a decrease in the entrained air fraction because the presence of a considerable umbrella region and a partial collapse of the column that are not considered by 1D models (see Discussion section).

Another key difference amongst models shows up in the plume radius (Fig. 8). As noted for the weak plume, the 1D assumption of constantly increasing radius all the way up to the plume top that is predicted by 1D models (with the exception of model \#5) is in clear disagreement with 3D cases. In particular, 1D models overpredict the plume radius by up to a factor of 8 above the level of neutral buoyancy, yet underestimate the radius below this level (Fig. 8). Despite these significant differences, the 1D maximum heights match their 3D counterparts reasonably well.

\subsection{Model sensitivity}

Some research groups carried out sensitivity analyses on boundary conditions and model parameters related to: $i$ ) air entrainment, $i$ ) water phase change; $i i i)$ effect of humidity, $i v$ ) particle fallout; $v$ ) particle re-entrainment, $v i$ ) particle aggregation. 
Concerning air entrainment, as we described above (see Section 2. Models), most of the models use two entrainment coefficients, one for the radial entrainment, $\alpha$, and another for wind entrainment, $\beta$, while models 5 and 6 parameterize entrainment as a function of the local Richardson number. All participants carried out a sensitivity study on $\alpha$, using the range $0.05-0.15$, and on $\beta$, using the range 0.1-1.0. Models adopting functional forms for the entrainment coefficients investigated the sensitivity on the empirical parameters characterizing the entrainment functions in addition to the ranges for $\alpha$ and $\beta$.

Participants also compared the following cases:

1- $a$ ) with and $b$ ) without those effects;

2- a) considering only the two classes representative of coarse and fine particles and $b$ ) accounting for a particle distribution given by the sum of two lognormal distributions (Gaussian in $\Phi$ ) as explained in Section 3 (considered only by models that describe the fallout of particles).

For models that include a description of the phase change of water and humidity effects, participants compared cases:

3- $a$ ) with and $b$ ) without those effects;

Similarly, models that account for particle aggregation effects carried out simulations:

4- $a$ ) with and $b$ ) without those effects;

The response of each model to typical uncertainties in the values for input parameters was explored, in particular considering:

- MER ranging from $1 / 5$ to 5 times the reference values for weak and strong plumes respectively; 
- eruption column heights varying by $\pm 20 \%$ of the reference value for weak and strong plumes respectively;

- variation of the exit velocity by $\pm 30 \%$ of the reference value for weak and strong plumes respectively;

- exit temperature deviating by $\pm 100{ }^{\circ} \mathrm{C}$ from the reference value for weak and strong plumes respectively;

- exit magma water fractions deviating by $\pm 2 \mathrm{wt} \%$ from the reference value for weak and strong plumes respectively.

Here we summarize the main results obtained from the sensitivity studies performed by the participating groups. Further details related to each model can be found in the specific contributions of this issue.

The research groups performed a sensitivity analysis using a variety of approaches and focussing on different aspects.

Pouget et al. (this issue) used the Conjugate Unscented Transform (CUT) routine to calculate moment-dependent variance-based sensitivity indices with $\sim 50$ simulations. They then carried out millions of runs to sample the multidimensional space of inputs, parameters, and global sensitivity indices. Woodhouse et al. (this issue) used a Latin Hypercube design for sampling model input space, and adopted variance-based sensitivity indices to quantify the model response. de' Michieli Vitturi et al. (this issue) carried out thousands of simulations varying governing parameters and initial conditions, and describe the results by density distributions of the maximum plume heights or MERs. Macedonio et al. (this issue) performed a simple parametric and sensitivity study by varying governing parameters and initial conditions one-at-a-time and switching some of physical effects on and off. Finally, Girault et al. (this issue) 
studied the effect of total grain size distribution and wind intensity on eruptive column dynamics.

Comparing model outputs against the scaling relationship of Degruyter and Bonadonna (2012) and Woodhouse et al. $(2013,2015)$ can give some insight into the parameters that influence the MER estimate. The choice of entrainment coefficients is very important. In the case of a strong plume, the radial entrainment will be dominant over the wind entrainment, and MER $\sim \alpha^{2}$. A difference between the minimum and maximum value for $\alpha$ by a factor of 3 can thus result in a factor of 9 difference in the estimated MER. In the case of a weak plume, the wind entrainment will be dominant, and we will have MER $\sim \beta^{2}$. Considering a factor of 10 difference between the minimum and maximum values for the wind entrainment coefficient (as the widest range of uncertainty) would result in a factor of 100 difference in the MER estimate. When the radius of a bent-over plume is taken into account in the comparison of the modelled rise height (Mastin, 2014) with the observed rise height, the sensitivity to changes in $\beta$ is reduced for typical values of $\beta$ (Devenish, this issue). In simulations with fixed height, the influence of the target height, $H$, also varies between a strong and a weak plume. For a strong plume we have MER $\sim H^{4}$. Thus, a $20 \%$ increase in height will result in a factor of $(1.2)^{4} \approx 2.1$ increase in MER, while a $20 \%$ decrease will change the MER by a factor $(0.8)^{4} \approx 0.41$. For a weak plume, we have MER $H^{3}$ and thus the change in MER will be less sensitive to changes in height. A $20 \%$ increase in height will result in a factor of $(1.2)^{3} \approx 1.7$ increase in MER, while a $20 \%$ decrease will change the MER by a factor $(0.8)^{3} \approx 0.51$. The MER is inversely proportional to the magma temperature, independent of having a weak or strong plume. A change in 100 degrees is roughly equivalent to a change in $10 \%$ in the estimate of the MER, and thus provides only a weak influence. The exit velocity (and 
the exit magma water fraction for Degruyter and Bonadonna, 2012) does not appear the relationship between MER and height. Note that this does not mean these quantities do not affect height, as they influence the MER. Furthermore, these are quantities important to the collapse condition (Bursik and Woods, 1991; Degruyter and Bonadonna, 2013).

Varying the MERs by a factor of five (considered as typical of the uncertainty in estimates of this quantity) changes the column heights by $\sim 30-50 \%$ for strong plumes and $40-80 \%$ for weak plumes (Macedonio et al., this issue; de' Michieli Vitturi et al., this issue; Pouget et al., this issue; Woodhouse et al., this issue). Note that a scaling relationship $H \sim \mathrm{MER}^{1 / 4}$ would result in a height increase of $\sim 50 \%$ for an increase in the MER by a factor of five, and $\sim 30 \%$ for a decrease in the MER by a factor of five (see Woodhouse et al., this issue). When inferring MER from plume height, increasing the height by $20 \%$ results in an increase in the MER of $\sim 150-200 \%$ while decreasing the plume height by $20 \%$ results in a reduction of the MER by $\sim 50-70 \%$.

The sensitivity studies showed that a variation of the entrainment coefficients within the assigned ranges (that are mostly based on laboratory measurements) have similar effects on model outputs as the typical uncertainty associated with the MER, producing variations in the column heights of $10-15 \%$ for strong plumes and $30-60 \%$ for weak plumes (Macedonio et al., this issue; de' Michieli Vitturi et al., this issue; Pouget et al., this issue; Woodhouse et al., this issue). This strong dependence needs to be considered when inferring MER from plume height, considering fixed entrainment coefficients, as this introduces uncertainties in the inferred values of up to a factor of three, consistent with previous sensitivity analyses (Carazzo et al., 2008) and uncertainty analyses (Woodhouse et al., 2015). 
By varying the initial conditions (initial velocity, temperature, gas mass fraction and, wind speed), de' Michieli Vitturi et al. (this issue) identified the initial water fraction as the dominant control on the column height in both the strong wind and weak wind case, with the initial velocity and wind also playing a minor role. This behaviour was also found by Macedonio et al. (this issue). However, for the strong plume, both with and without wind effects, there is the possibility of column collapse ( $<10 \%$ in windless cases and $<1 \%$ in windy cases) for some values of the exit velocity, showing that, in these cases, there is a strong control of this parameter on the plume dynamics (de' Michieli Vitturi et al., this issue; Woodhouse et al., this issue). The additional entrainment due to wind enables plumes that would collapse when wind is neglected to incorporate enough air to become buoyant (de' Michieli Vitturi et al., this issue; Pouget et al., this issue).

The source temperature only weakly influences the plume height, with changes smaller than one percent for the weak plume cases and less than $5 \%$ for the strong plume cases (Macedonio et al., this issue; Woodhouse et al., this issue).

The results indicate that the description of particle sedimentation in plume models has a negligible effect on the predictions of the maximum plume height in these cases (Macedonio et al., this issue; de' Michieli Vitturi et al., this issue). However, Pouget et al. (this issue), although finding a lack of model sensitivity to particle mean grain-size at the vent, discovered a profound sensitivity to grain-size standard deviation. Moreover, the simulations of Girault et al. (this issue) show that the grain-size distribution at the maximum height of the plume is rather insensitive to the wind profile, but the maximum height of the plume decreases for any grain-size distribution in windy cases, especially for the large MERs $\left(>10^{7} \mathrm{~kg} \mathrm{~s}^{-1}\right)$. 
Most research groups (Macedonio et al., this issue; Woodhouse et al., this issue) found that neglecting the entrainment of atmospheric moisture varied plume heights by only a few percent for both the strong and weak plume cases. This insensitivity likely results from the dominance of magmatic energy relative to that of water vapour in the strong plume, and the relatively low temperature (and hence low atmospheric water content) in the weak plume (Macedonio et al., this issue). Macedonio et al. (this issue) found also that neglecting or accounting for latent heat released during water phase transitions is relatively negligible, being responsible for variations of column height and MER typically of a few percent and generally less than $\sim 10 \%$.

\section{Discussion}

\subsection{Insights from comparing $1 D$ and $3 D$ models}

One-dimensional models adopt many simplifying assumptions, and this study has emphasized that there are situations in which the current formulations of 1D models are not entirely appropriate. Our comparison of 1D and 3D models suggests that the simplified 1D treatment of entrainment was reasonable in the case of our weak plume scenario, but, although 1D models provide a reasonable maximum column height, it fails to reproduce entrainment patterns in the strong plume scenario. In fact, as shown in Fig. 4b, the eruption column simulated by 3D models entrains ambient air more efficiently in the lower part, whereas entrainment is less efficient in the upper region. These effects could offset one another, and as a result, the average efficiency of 3D entrainment may coincide (fortuitously) with that assumed in the simple 1D models. On the other hand, 1D models are clearly inadequate to capture some important features of the strong plume because of the greater complexity of the 
plume structures. For example, fountaining features near the vent, such as "radially suspended flow" (Neri and Dobran, 1994; Suzuki and Koyaguchi, 2012) could cause rapid variation in the efficiency of entrainment as illustrated in Fig. 4b. Although this fountain structure remained mostly or completely buoyant in some of the 3D models, in others, it led to partial column collapse and shedding of pyroclastic density currents along the ground, as has been described by Neri et al. (2002) and Van Eaton et al. (2012). In addition, in strong plumes, the gravitational fountaining of the eruptive mixture above the NBL forms umbrella clouds that are controlled by physical processes not accounted for by BPT models (e.g., Costa et al., 2013; Johnson et al., 2015). In particular, the vertical profiles of the entrained air fraction in the upper region of the plume reflect the mass concentration within the umbrella cloud, showing a very different behaviour with respect to the lower part of the plume (see Suzuki et al., this issue-b, for more details). These points deserve future investigation.

Despite these important discrepancies, the maximum column heights simulated by $1 \mathrm{D}$ and 3D models show relatively good agreement. The standard deviation in the calculated column height is $\sim 20 \%$ for the weak plume (Tables 6 and 8) and $\sim 10 \%$ for the strong plume cases (Tables 10 and 12). Predictions of the NBL are also in reasonably good agreement among 1D and 3D models, independent of the wind conditions, with a standard deviation ranging from $\sim 10$ to $\sim 20 \%$ (the latter for the windy, weak plume). Overall, these differences are well within the typical range of uncertainty in observations of column height, due to both the resolution of different methods, and actual variability in plume height.

Interestingly, for weak plumes, the variations in the vertical profiles of the species mass fractions, density, and temperature are small, whereas those for the radius and vertical velocity are large. However, there is a greater variation in the 
maximum column height predicted by the models for the weak plume than is found for the strong plume scenario, whereas the standard deviation of the NBL is smaller for the weak plume cases than that for strong plume case.

Global features of the plume, such as column height, are relatively consistent across the model types, while there are substantial differences in the local features, such as the behaviour of the physical quantities at different heights. This appears consistent also with findings by Koyaguchi and Suzuki (personal communication) who highlight that the trends of the critical conditions for column collapse on the basis of the three-dimensional simulations are almost the same as those predicted by the BPT models, even though the three-dimensional flow patterns (which control ground-based hazards such as pyroclastic-flow development during column collapse) are quite different from the ambient flow assumed in the BPT models.

\subsection{Implications for improving entrainment in $1 D$ models}

The fact that entrainment parameterizations adopted in the 1D models cannot describe fully the turbulent mixing due to fountaining structures was anticipated in the original study of Morton et al. (1956), and there have been attempts to represent the fountaining region in integral models (e.g., McDougall, 1981; Bloomfield and Kerr, 2000; Carazzo et al. 2010). Another possible explanation for the discrepancies described above can be due to the radial heterogeneity in the eruption column. Even if the entrainment of ambient air is efficient in weak plumes, the entrained mass fraction along the central axis of the flow is significantly larger than that in the outer region (see Suzuki and Koyaguchi, 2010; 2015), affecting the maximum height reached by the plume. Further investigations using 3D models would be necessary (see also Suzuki et al., submitted-a). 
Our results highlight the potential importance of incorporating a variable entrainment coefficient into 1D models to produce accurate profiles of the dynamical variables controlling the behaviour of volcanic plumes. The predictions made by $1 \mathrm{D}$ models in which the entrainment coefficient is a function of the local buoyancy of the plume (models \#5 and \#6) are consistent with one another, but slightly diverge from those made using fixed entrainment coefficients, when comparing the air fraction entrained into the plume (Fig. 4), the gas and solid fractions along the plume (Figs. 6 and 9), the plume temperature (Fig. 10), and the plume velocity profiles (Fig. 11). However, there remains a discrepancy between the profiles produced by the 1D models with variable entrainment coefficients and those calculated by 3D models.

\subsection{Models limitations and future developments}

There are features, such as the behaviour of the plume above the NBL, that are poorly represented in 1D models, as the assumptions on which the 1D models are based are not strictly appropriate above the NBL where 1D models overpredict plume radius at the top of the column. The overprediction can lead to errors to plume volume; and to total plume height in cases where this value is calculated by adding radius to the centreline height (Mastin, 2014). The behaviour of the radius and the gas or solid fractions found by the three-dimensional models, is captured only by model \#5, which uses a semi-empirical description in this region, although quantitative agreement is still lacking.

Results highlight the need for a consideration of the eruption column models used for operational purposes, when there is a need to estimate MER for tephra transport models (especially for windy weak plumes), but also that the variability among models is quite close to typical uncertainties characterizing column heights. 
The 1D models are particularly useful in providing boundary conditions for tephra transport models, as observations of the volcanic plume can be used to derive estimates of the MER through model inversions, and the rapid 1D models can be applied in operational contexts. However, the comparison of the 1D models among themselves and with 3D models highlights the need for careful consideration in this application of plume models.

The results reported here and in the sensitivity analyses of the individual models show that the different model formulations adopted in the $1 \mathrm{D}$ models (in particular the choice of entrainment coefficients) leads to variability in the predicted column height. As the variability is quite close to typical uncertainties in column height observations, inversions that match model predictions to column height observations are not sufficient to calibrate the model parameters (see also Woodhouse et al. 2015). This impacts on the uncertainty in predictions of the MER, as the results demonstrate. For a fixed column height, the MERs predicted by 1D models range from $\sim 50 \%$ standard deviation for no-wind strong plumes (Table 11) to $\sim 100 \%$ for windy weak plumes (Table 9). In Europe, where Volcanic Ash Advisories issued during eruptions include model-based maps of ash concentration in the cloud, uncertainties of $\sim 100 \%$ in MER, used in model input, translate directly to $100 \%$ uncertainty in ash-cloud concentration at a given place and time.

When estimating MER using models, the uncertainties in the model formulation should be quantified and incorporated into model inversion alongside uncertainties in column height observations. Woodhouse et al., (2015) have demonstrated a method for including uncertainties in parameters, observations, numerical methods, and the model structure (i.e. the parameterizations adopted, and the unmodeled physical processes). While it is relatively straightforward to sample 
uncertain parameter values from a distribution, quantifying the structural uncertainty in a model is more difficult (Woodhouse et al., 2015).

This study represents an important contribution to assessing the structural uncertainty in 1D plume models. The comparison of 1D models that include different physical processes (e.g. with or without moisture, particle fallout, aggregation etc.) and parameterizations (e.g. constant or variable entrainment rates) allows an assessment of the influence of these model choices on the predictions. Our result indicate that the neglect of water phase changes, particle fallout and aggregation in the 1D models has a relatively small effect on the prediction of the column height or the inferred MER in comparison to the differences due to the values taken for the model parameters (e.g. Macedonio et al, this issue).

Including 3D models in the comparison allows a more detailed assessment of the structural uncertainty in 1D models, although we must be cautious in comparing one class of models with another. The column heights determined by $1 \mathrm{D}$ and $3 \mathrm{D}$ models for specified MER are relatively consistent for the weak plume, and therefore the use of $1 \mathrm{D}$ models does not appear to introduce large structural uncertainties through the simplified description of entrainment when considering only the column height. However, there is a greater structural uncertainty for the strong plume case. Furthermore, the substantial differences observed in the profiles of column properties indicates that the structural uncertainty introduced by adopting a 1D model should be included when comparing local properties of the column (e.g. the radius, velocity, temperature, etc.) to observations, and further model development is needed in order for $1 \mathrm{D}$ models to provide robust predictions of these local properties.

Another point that should be kept in mind when we compare 1D models with $3 \mathrm{D}$ models and observations is that the NBL (defined as the level where the cross- 
sectional integral of the reduced gravity changes signs) does not coincide with the Maximum Spreading Level (MSL, defined as the level where the vertical profile of the mass fraction reaches its maximum width). For example, the NBL lies $\sim 4-5 \mathrm{~km}$ below the MSL for strong plume cases, and $\sim 1 \mathrm{~km}$ for the weak plume cases considered in this study (Suzuki et al., submitted-a). This point is important when 1-D plume model output is integrated into dispersion models.

There are other limitations in the 1D model of Morton et al. (1956) related to the steady-state assumption (i.e. the plume is in a statistically steady-state), whereas the 3D models are fundamentally unsteady. 1D models can account for unsteadiness due to transient changes in the source and atmospheric conditions (Delichatsios, 1979; Yu, 1990, Vul'fson and Borodin, 2001; Scase et al., 2006, 2008; Craske and van Reeuwijk, 2015a, 2015b; Woodhouse et al., submitted) but the formulation of these unsteady models requires additional physical processes to be modelled. In particular, 1D unsteady models that adopt top-hat descriptions of radial plume properties are illposed and require regularization through the inclusion of diffusion of axial momentum (Scase and Hewitt, 2012), although this leads to fundamental changes to the steady solutions (Woodhouse et al., submitted).

The results also highlight some confusion in terminology, as the difference between weak plumes and strong plumes is often related only to wind intensity with respect to plume velocity. Unfortunately, the terminology that has been adopted to categorize plumes as weak or strong does not account for the fundamental difference in the dynamics caused by the differences in the turbulence structure due to the formation of the umbrella region. The standard categorization is based on the dimensionless ratio of the wind speed to the characteristic vertical velocity of the plume. When the wind speed is much smaller than the eruption velocity, an eruption 
column tends to rise almost vertically as a strong plume. Otherwise the plume trajectory is substantially bent over to produce a weak plume. However, while wind intensity controls whether the plume will be bent over or not, the plume dynamics are dependent on the MER, even for windless cases (see Suzuki et al, submitted-b). This suggests a more detailed categorization is needed, with an appropriate dimensionless number based on the MER. Simulations carried out by Suzuki et al. (submitted-b), for windless conditions, suggest that the transition from the weak to the strong plume regime occurs gradually, consistent with laboratory experiments (Carazzo et al., 2014). This transition occurs at MERs larger than $10^{7}-10^{8} \mathrm{~kg} / \mathrm{s}$ (around the boundary between small-moderate and subplinian eruptions suggested by Bonadonna and Costa, 2013) and roughly coincides with the shift from a self-similar jet-like flow to the fountain-like flow (Suzuki et al., submitted-b).

Finally, comparison of the predictions made using 1D and 3D models with well-constrained eruption datasets would certainly be valuable to validate the plume models. Girault et al. (this issue) propose a specially assembled set of natural data that could be used in the future to this purpose.

\section{Conclusions}

We have presented results from an inter-comparison study of different volcanic plume models, including simple 1D integral models and 3D models. The exercises carried out in the study ware designed as a blind test in which a set of common volcanological input parameters was given for two case studies, representing a strong and a weak plume, under different meteorological conditions.

A comparison of the predictions of models across the two categories showed that for weak plumes, independent of the category, all models gave very similar results for 
the variation of plume variables with height. However there is a relatively large discrepancy in the prediction of the total column height produced by each model for an assigned MER, especially for windy conditions, highlighting the needs and possibility to improve the current modelling approach in this case.

A comparison of the results obtained for strong plumes showed that there are substantial differences in the predictions of local properties of the plume between the two categories of models. This indicates, perhaps, that the parameterization of turbulent mixing that is commonly invoked in 1-D models is an incomplete description of the complex fluid motion that is induced in the ambient air in this regime. However, models based on BPT predict total column heights that are consistent with those calculated by 3-D models, highlighting the need to better understand this feature of 1-D models, and carry out further research to improve the estimation of the plume variables for strong plumes.

For both strong and weak plumes, this inter-comparison study has emphasized the strong control of the entrainment processes on plume dynamics. More sophisticated entrainment parameterizations may result in improved consistency between the predictions of local plume properties obtained by the two classes of models. However, this is likely to come at a cost of greater uncertainty in the value of empirical parameters. Therefore, a balance must be maintained between simplicity and accuracy, and this must be guided by the requirements of the model. For example, if estimates of the plume height for a specified MER are required (or the inverse of this problem), then the currently adopted entrainment parameterizations may be sufficient, given the typical uncertainty in making observations. On the other hand, if predictions of the local properties are required, for example the evolution of the composition of the plume with distance from the source, then a detailed local 
description of turbulent mixing is likely necessary. The execution and analysis of 3-D models to provide this information takes hours to days (or longer), whereas 1-D models require only minutes. Thus for the foreseeable future 3-D models will continue to be valuable for research and model validation, without being used during near-real time response to eruption crises.

There is a need and opportunity for further development of plume models of both types, and to examine the predictions of these models using field observations. There is a particular necessity to enhance the cooperation between experimentalists and researchers who use 1-D and 3-D models, especially for strong plumes with complex dynamics (e.g., umbrella formation, column instability) that cannot be easily reproduced in the laboratory.

Finally, a true validation of plume models will require systematic comparison with well-constrained natural eruptions. We hope to make this a future endeavour, using high-quality data collected during future events.

Acknowledgements. AC was partially supported by a grant of the International Research Promotion Office Earthquake Research Institute, the University of Tokyo. AC, GM, AN, MdMV, TEO and MC were partially supported by the EU-funded project MEDiterranean SUpersite Volcanoes (MEDSUV) (grant n. 308665). AVE acknowledges NSF Postdoctoral Fellowship EAR1250029 and a USGS Mendenhall Fellowship. MIB was supported partially by NSF-IDR and AFOSR. AJH, MJW, and JCP were partially supported by the NERC-funded project Vanaheim (grant no. NE/I01554X/1) and the EU-funded project FutureVolc (grant no. 308377). FG, GC, ST, and EK were partially supported by INSU-CNRS. We wish to thank T. 
Koyaguchi, S. Solovitz, and an anonymous reviewer for constructive suggestions that improved the quality of the manuscript.

\section{References}

Balachandar, S., Eaton, J.K., 2010. Turbulent Dispersed Multiphase Flow. Annu. Rev. Fluid Mech. 42, 111-133, doi:10.1146/annurev.fluid.010908.165243.

Bloomfield, L.J., Kerr, R.C., 2000. A theoretical model of a turbulent fountain. $J$. Fluid Mech. 424, 197-216, doi:10.1017/S0022112000001907.

Bonadonna, C., Costa, A., 2013. Plume height, volume, and classification of explosive volcanic eruptions based on the Weibull function. Bull. Volc. 75, 742, 1-19, doi: 10.1007/s00445-013-0742-1.

Briggs, G.A., 1975. Plume rise predictions. In Lectures on Air Pollution and Environmental Impact Analyses (ed. D. A. Haugen), pp. 59-111. American Meteorological Society.

Briggs, G.A., 1984. Plume rise and buoyancy effects. In Atmospheric Science and Power Production (ed. D. Randerson), pp. 327-366. Office of Research, US Department of Energy.

Bursik, M., 2001. Effect of wind on the rise height of volcanic plumes. Geophys. Res. Lett. 28 (18), 3621-3624, doi:10.1029/2001GL013393.

Carazzo, G., Girault, F., Aubry, T., Bouquerel, H., and Kaminski, E., 2014. Laboratory experiments of forced plumes in a density-stratified crossflow and implications for volcanic plumes. Geophys. Res. Lett. 41, 8759-8766, doi:10.1002/2014GL061887.

Carazzo, G., Kaminski, E., and Tait, S., 2008. On the rise of turbulent plumes: Quantitative effects of variable entrainment for submarine hydrothermal vents, 
terrestrial and extra terrestrial explosive volcanism. J. Geophys. Res. 113, B09201, doi:10.01029/02007JB005458.

Carazzo, G., Kaminski, E., and Tait, S., 2010. The rise and fall of turbulent fountains: a new model for improved quantitative predictions. J. Fluid Mech 657, 265-284, doi:10.1017/S002211201000145X.

Carazzo, G., Kaminski, E., Tait, S., 2006. The route to self-similarity in turbulent jets and plumes. J. Fluid Mech. 547, 137-148.

Carcano, S., Bonaventura, L., Esposti Ongaro, T., Neri, A., 2013. A semi-implicit, second-order accurate numerical model for multiphase underexpanded volcanic jets. Geosci. Model Dev. 6, 1905-1924.

Cerminara, M. 2015. The Multiphase Buoyant Plume Solution of the Dusty Gas Model, arXiv preprint arXiv:1506.01638.

Cerminara, M., Esposti Ongaro, T., Neri, A., (this issue). Large-eddy simulation of kinematic decoupling and turbulent entrainment in volcanic gas-particle plumes. Submitted to J. Volcanol. Geoth. Res.

Cerminara, M., Esposti Ongaro, T., and Berselli, L. C., 2016. ASHEE: a compressible equilibrium-Eulerian model for volcanic ash plumes. Geosci. Model Dev., in press.

Contini, D., Donateo, A., Cesari, D., Robins, A.G., 2011. Comparison of plume rise models against water tank experimental data for neutral and stable crossflows. $J$. Wind. Eng. Ind Aerodyn. 99, 539-553

Costa, A., Folch, A., Macedonio, G., 2013. Density-driven transport in the umbrella region of volcanic clouds: Implications for tephra dispersion models. Geophys. Res. Lett. 40, 4823-4827, doi: 10.1002/grl.50942 
Craske, J., and van Reeuwijk, M., 2015b. Energy dispersion in turbulent jets. Part 2. A robust model for unsteady jets. J. Fluid Mech. 763, 538-566.

Craske, J., van Reeuwijk, M., 2015a. Energy dispersion in turbulent jets. Part 1. Direct simulation of steady and unsteady jets. J. Fluid Mech. 763, 500-537.

Davidson, G.A. 1986. Gaussian versus top-hat profile assumptions in integral plume models. Atm. Env. 20 (3), 471-478.

de’Michieli Vitturi, M., Engwell, S.L., Neri, A., Barsotti, S., (this issue). Uncertainty Quantification and Sensitivity Analysis of volcanic columns: results from the integral model PLUME-MoM. J. Volcanol. Geoth. Res., accepted.

de’Michieli Vitturi, M., Neri, A., Barsotti, S., 2015. PLUME-MoM: a new integral model of volcanic plumes based on the method of moments, Geosci. Model Dev. 8, 2447-2463, doi:10.5194/gmd-8-2447-2015.

Degruyter, W., Bonadonna, C., 2012. Improving on mass flow rate estimates of volcanic eruptions. Geophys. Res. Lett. 39, L16308, doi: 10.1029/ 2012GL052566.

Degruyter, W., Bonadonna, C., 2013. Impact of wind on the condition for column collapse of volcanic plumes, Earth Planet. Sci. Lett. 377, 218-226

Delichatsios, M.A., 1979. Time similarity analysis of unsteady buoyant plumes in neutral surroundings. J. Fluid Mech. 93, 241-250.

Devenish, B.J., (this issue). Estimating the total mass emitted by the eruption of Eyjafjallajokull in 2010 using plume-rise models. J. Volcanol. Geoth. Res., accepted.

Devenish, B.J., 2013. Using simple plume models to refine the source mass flux of volcanic eruptions according to atmospheric conditions. J. Volcanol. Geoth. Res. 256, 118-127. 
Devenish, B.J., Rooney, G.G., Webster, H.N., Thomson, D.J., 2010. The entrainment rate for buoyant plumes in a crossflow. Boundary-Layer Meteorol. 134, 411439, doi:10.1002/ 2013JD020604.

Elghobashi, S., 1991. Particle-laden turbulent flows: direct simulation and closure models. Applied Scientific Research 48, 301-314.

Elghobashi, S., 1994. On predicting particle-laden turbulent flows. Applied Scientific Research 52, 309-329.

Ernst, G.G.J., Sparks, R.S.J., Carey, S.N., Bursik, M.I., 1996. Sedimentation from turbulent jets and plumes. J. Geophys. Res. 101 (B3), 5575-5589.

Esposti Ongaro, T., Cavazzoni, C., Erbacci, G., Neri, A., Salvetti, M.V., 2007. A parallel multiphase flow code for the 3D simulation of explosive volcanic eruptions. Parallel Computing 33 (7), 541-560.

Esposti Ongaro, T., Cerminara, M., (this issue) Non-equilibrium processes in ashladen volcanic plumes: new insights from 3D multiphase flow simulations. Submitted to J. Volcanol. Geoth. Res.

Fay, J.A., Escudier, M., Hoult, D.P., 1969. A correlation of field observations of plume rise. Publication No. 69-4, Fluid Mechanics Laboratory, Massachusetts Institute of Technology.

Ferry, J., Balachandar, S., 2001. A fast Eulerian method for disperse two-phase flow. Int. J. Multiphase Flow 27, 1199-1226.

Folch, A., Costa, A., Macedonio, G., 2015. FPLUME-1.0: An integral volcanic plume model accounting for ash aggregation. Geosci. Model Dev., 9, 1-20, doi:10.5194/gmd-9-1-2016.

Friedlingstein, P., Cox, P., Betts, R., Bopp, L., von Bloh, W., Brovkin, V., Cadule, P., Doney, S., Eby, M., Fung, I., Bala, G., John, J., Jones, C., Joos, F., Kato, T., 
Kawamiya, M., Knorr, W., Lindsay, K., Matthews, H.D., Raddatz, T., Rayner, P., Reick, C., Roeckner, E., Schnitzler, K.-G., Schnur, R., Strassmann, K., Weaver, A. J., Yoshikawa, C., Zeng, N., 2006. Climate-Carbon Cycle Feedback Analysis: Results from the C4MIP Model Intercomparison. J. Climate 19, $3337-3353$.

Gates, W.L., Boyle, J.S., Covey, C., Dease, C.G., Doutriaux, C.M., Drach, R.S., Fiorino, M., Gleckler, P.J., Hnilo, J.J., Marlais, S.M., Phillips, T.J., Potter, G.L., Santer, B.D., Sperber, K.R., Taylor, K.E., Williams, D.N., 1999. An Overview of the Results of the Atmospheric Model Intercomparison Project (AMIP I). Bull. Amer. Meteor. Soc. 80, 29-55.

Girault, F., Carazzo, G., Tait, S., Ferrucci, F., Kaminski, É., 2014. The effect of total grain-size distribution on the dynamics of turbulent volcanic plumes. Earth Planet. Sci. Lett. 394, 124-134.

Girault, F., Carazzo, G., Tait, S., Kaminski, E., (this issue). Combined effects of total grain-size distribution and crosswind on the rise of eruptive volcanic columns. J. Volcanol. Geotherm. Res., doi:10.1016/j.jvolgeores.2015.11.007.

Glaze, L.S., Baloga, S.M., 1996. Sensitivity of buoyant plume heights to ambient atmospheric conditions: Implications for volcanic eruption columns. $J$. Geophys. Res. 101 (D1), 1529-1540.

Glaze, L.S., Baloga, S.M., Wilson, L., 1997. Transport of atmospheric water vapor by volcanic eruption columns. J. Geophys. Res. 102 (D5), 6099-6108.

Hashimoto, A., Shimbori, T., Fukui, K., 2012. Tephra fall simulation for the eruptions at Mt. Shinmoe-dake during 26-27 January 2011 with JMANHM. SOLA 8, 3740. 
Hewett, T.A., Fay, J.A., Hoult, D.P., 1971. Laboratory experiments of smokestack plumes in a stable atmosphere. Atmos. Environ. 5, 767-789.

Holasek, R., Self, S., Woods, A., 1996. Satellite observations and interpretation of the 1991 Mount Pinatubo eruption plumes, J. Geophys. Res. 101 (B12), 2763527655.

Hoult, D.P., Fay, J.A., Forney, L.J., 1969. A theory of plume rise compared with field observations. J. Air. Pollut. Control. Assoc. 19, 585-590.

Hoult, D.P., Weil, J.C., 1972. Turbulent plume in a laminar cross flow. Atmos. Environ. 6, 513-531.

Hunt, G. R., and van den Bremer, T.S., 2010. Classical plume theory: 1937-2010 and beyond. IMA J. Appl. Math. 76, 424-448.

Huq, P., Stewart, E.J., 1996. A laboratory study of buoyant plumes in laminar and turbulent crossflows. Atmos. Environ. 30, 1125-1135.

Johnson, CG, Hogg, AJ, Huppert, HE, Sparks, RSJ, Phillips, JC, Slim, AC \& Woodhouse, MJ, 2015. Modelling intrusions through quiescent and moving ambients. J. Fluid Mech., 71, 370-406.

Kaminski, E., Tait, S., Carazzo, G., 2005. Turbulent entrainment in jets with arbitrary buoyancy. J. Fluid Mech. 526, 361-376.

Koyaguchi, T. and Tokuno, M., 1993. Origin of the giant eruption cloud of Pinatubo, June 15, 1991. J. Volcanol. Geotherm. Res., 55: 85-96.

Kozono, T., Ueda, H., Ozawa, T., Koyaguchi. T., Fujita, E., Tomiya, A., Suzuki, Y.J., 2013. Magma discharge variations during the 2011 eruptions of Shinmoe-dake volcano, Japan, revealed by geodetic and satellite observations, Bull. Volcanol. 75, 695, doi:10.1007/s00445-013-0695-4. 
Lesieur, M., Métais, O., Comte, P., 2005. Large-Eddy Simulations of Turbulence, Large-Eddy Simulations of Turbulence, by M. Lesieur and O. Métais and P. Comte, pp. 248. ISBN 0521781248. Cambridge, UK: Cambridge University Press, August 2005.

List, E.J., 1982. Turbulent jets and plumes. Annu. Rev. Fluid Mech. 14, 189-212.

Macedonio, G., Costa, A., Folch, A., (this issue). Uncertainties in volcanic plume modeling: a parametric study using FPLUME. J. Volcanol. Geoth. Res., submitted.

Marble, F.E., 1970. Dynamics of dusty gases. Annual Review of Fluid Mechanics, 2 (1), 397-446.

Mastin, L.G., 2007. A user-friendly one-dimensional model for wet volcanic plumes, Geochem., Geophys. Geosyst. 8, Q03014, doi:10.1029/2006GC001455.

Mastin, L.G., 2014. Testing the accuracy of a 1-D volcanic plume model in estimating mass eruption rate, J. Geophys. Res. Atmos. 119, 2474-2495,

Mastin, L.G., Guffanti, M., Servranckx, R., Webley, P., Barsotti, S., Dean, K., Durant, A., Ewert, J.W., Neri, A., Rose, W.I., Schneider, D., Siebert, L., Stunder, B., Swanson, G., Tupper, A., Volentik, A., Waythomas, C.F., 2009. A multidisciplinary effort to assign realistic source parameters to models of volcanic ash-cloud transport and dispersion during eruptions. J. Volcanol. Geotherm. Res. 186, 10-21.

McDougall, T.J., 1981. Negatively buoyant vertical jets. Tellus 33, 313-320, doi:10.1111/j.2153-3490.1981.tb01754.x.

Morton, B.R., 1957. Buoyant plumes in a moist atmosphere. J. Fluid Mech. 2, 127144. 
Morton, B.R., Taylor, G.I., Turner, J.S., 1956. Turbulent gravitational convection from maintained and instantaneous source. Phil. Trans. Roy. Soc. Lond. A 234, $1-23$.

Neri, A., Dobran, F., 1994. Influence of eruption parameters on the thermofluid dynamics of collapsing volcanic columns. J. Geophys. Res. 99 (B6), 1183311857.

Neri, A., Di Muro, A., Rosi, M., 2002, Mass partition during collapsing and transitional columns by using numerical simulations. J. Volcanol. Geotherm. Res. 115, 1-18.

Neri, A., Esposti Ongaro, T., Macedonio, G., Gidaspow, D., 2003. Multiparticle simulation of collapsing volcanic columns and pyroclastic flow. J. Geophys. Res. 108 (B4), 2202.

Nicoud, F., Ducros, F., 1999. Subgrid-scale stress modelling based on the square of the velocity gradient tensor. Flow, Turbulence and Combustion, pp. 1-36.

Pouget, S., Bursik, M., Singla, P., Singh, T. (this issue). Sensitivity analysis of a onedimensional model of a volcanic plume with particle fallout and collapse behavior. J. Volcanol. Geoth. Res., accepted.

Priestley, C.H.B., 1956. A working theory of the bent-over plume of hot gas, Quarterly J. Roy. Met. Soc., 82, 165-176.

Priestley, C.H.B., Ball, F.K., 1955. Continuous convection from an isolated source of heat. Quarterly J. Roy. Met. Soc. 81 (348), 144-157.

Ricou, F., Spalding, D., 1961. Measurements of entrainment by axisymmetrical turbulent jets, J. Fluid Mech., 11, 21-32.

Sahagian, D., 2005. Volcanic eruption mechanisms: insights from intercomparison of models of conduit processes. J. Volcanol. Geotherm. Res. 143, 1-15. 
Scase, M.M., Caulfield, C.P., Dalziel, S.B., 2008. Temporal variation of non-ideal plumes with sudden reductions in buoyancy flux. J. Fluid Mech. 600, 181-199.

Scase, M.M., Caulfield, C.P., Dalziel, S.B., Hunt, J.C.R., 2006. Time-dependent plumes and jets with decreasing source strengths. J. Fluid Mech. 563, 443-461.

Scase, M.M., Hewitt, R.E., 2012. Unsteady turbulent plume models. J. Fluid Mech. $697,455-480$.

Sparks, R.S.J., 1986. The dimensions and dynamics of volcanic eruption columns. Bull. Volcanol. 48, 3-15.

Sparks, R.S.J., Bursik, M.I., Carey, S.N., Gilbert, J.S., Glaze, L.S., Sigurdsson, H. and Woods, A.W., 1997. Volcanic Plumes. John Wiley \& Sons, Chichester, 574 pp.

Suzuki, Y.J., Costa, A., and Koyaguchi, T., (this issue-b). On the relationship between eruption intensity and volcanic plume height: insights from three-dimensional numerical simulations. J. Volcanol. Geoth. Res., submitted.

Suzuki, Y.J., Costa, A., Cerminara, M., Esposti Ongaro, T., Herzog, M., Van Eaton, A., Denby, L.C., (this issue-a). Inter-comparison of three-dimensional models of volcanic plumes. Submitted to J. Volcanol. Geoth. Res.

Suzuki, Y.J., Koyaguchi, T., 2009. A three-dimensional numerical simulation of spreading umbrella clouds. J. Geophys. Res. 114, B03209, doi:10.1029/2007/JB005369.

Suzuki, Y.J., Koyaguchi, T., 2013. 3D numerical simulation of volcanic eruption clouds during the 2011 Shinmoe-dake eruptions. Earth Planets Space, 65 (6), 581-589, doi:10.5047/eps.2013.03.009.

Suzuki, Y.J., Koyaguchi, T., 2015. Effects of wind on entrainment efficiency in volcanic plumes. J. Geophys. Res. 120, doi:10.1002/2015JB012208. 
Suzuki, Y.J., Koyaguchi, T., Ogawa, M., Hachisu, I., 2005. A numerical study of turbulent mixing in eruption clouds using a three-dimensional fluid dynamics model. J. Geophys. Res. 110, B08201, doi:10.1029/2004JB003460.

Turner, J.S., 1986. Turbulent entrainment: the development of the entrainment assumption, and its application to geophysical flows. J. Fluid Mech. 173, 431471.

Van Eaton, A.R., Herzog, M., Wilson, C.J.N., McGregor, J., 2012, Ascent dynamics of large phreatomagmatic eruption clouds: the role of microphysics. J. Geophys. Res. 117, B03203, doi:10.1029/2011JB008892.

Vul'fson, A.N. Borodin, O.O., 2001. Self-similar propagation regimes of a nonstationary high-temperature convective jet in the adiabatic atmosphere. $J$. Appl. Mech. Tech. Phy. 42 (2), 255-261.

Weil, J.C., 1974. The rise of moist, buoyant plumes. J. Appl. Meteorol. 13, 435-443.

Weil, J.C., 1988. Plume rise. In: Venkatram. A., Wyngaard, J.C. (eds) Lectures on air pollution modelling. American Meteorological Society, Boston, pp 119-166.

Woodhouse, M.J., Hogg, A.J., Phillips, J.C., (this issue). A global sensitivity analysis of the PlumeRise model of volcanic plumes. J. Volcanol. Geoth. Res., accepted.

Woodhouse, M.J., Hogg, A.J., Phillips, J.C., Rougier, J.C., 2015. Uncertainty analysis of a model of wind-blown volcanic plumes. Bull. Volcanol. 77 (10), doi: $10.1007 / \mathrm{s} 00445-015-0959-2$

Woodhouse, M.J., Phillips, J.C., and Hogg, A.J., (submitted). Unsteady turbulent buoyant plumes. J. Fluid Mech., available on the arXiv at http://arxiv.org/abs/1507.06571 
Woodhouse, M.J., Hogg, A.J, Phillips, J.C., Sparks, R.S.J., 2013. Interaction between volcanic plumes and wind during the 2010 Eyjafjallajokull eruption, Iceland. $J$. Geophys. Res. Solid Earth, 118, 92-109,doi:10.1029/2012JB009592.

Woods, A.W., 1988. The fluid dynamics and thermodynamics of eruption columns. Bull. Volcanol. 50, 169-193.

Woods, A.W., Bursik, M.I., 1991. Particle fallout, thermal disequilibrium and volcanic plumes. Bull. Volcanol. 53, 559-570.

Woods, A.W., Bower, S.M., 1995. The decompression of volcanic jets in a crater during explosive volcanic eruptions. Earth Planet. Sci. Lett. 131, 189-205.Yu, H.-Z., 1990. Transient plume influence in measurement of convective heat release rates of fast-growing fires using a large-scale fire products collector. $J$. Heat Transf. 112 (1), 186-191. 


\section{FIGURE CAPTIONS}

Fig. 1. Atmospheric conditions used for simulations were wind speed from west to east, wind speed from south to north, temperature, pressure, density, and specific humidity. (A) Atmospheric profiles for the weak plume scenario were provided by the Japan Meteorological Agency’s Non-Hydrostatic Model (Hashimoto et al., 2012), for Shinmoe-dake volcano at 00 JST on 27 January 2011; (B) Profiles for the strong plume scenario were obtained from the European Centre for Medium-Range Weather Forecasts (ECMWF) and corrected above $20 \mathrm{~km}$ by Costa et al. (2013), for Pinatubo volcano at 13:40 PLT of 15 June 1991.

Fig. 2. The predictions of column heights returned from each model (denoted by labels) for fixed MER. Red colour indicates 1D models, blue 3D models, green empirical relationships, black the average of 1D and 3D models.

Fig. 3. Predictions of the MER returned from each model (denoted by labels) for fixed column heights. Red colour indicates 1D models, blue 3D models (not used in this group of exercise), green empirical relationships, black the average of $1 \mathrm{D}$ and 3D models.

Fig. 4. The mass fraction of air entrained into the plume as a function of height for the different cases.

Fig. 5. The bulk mixture density of the plume as a function of height for the different cases. 
Fig. 6. The gas mass fraction of the plume as a function of height for the different cases.

Fig. 7. Profiles of the plume centreline position for the strong and weak plume cases when wind effects are accounted for.

Fig. 8. The radius of the plume as a function of height for the different cases.

Fig. 9. The mass fraction of solids in the plume as a function of height for the different cases.

Fig. 10. The temperature of the plume as a function of height for the different cases.

Fig. 11. The vertical velocity of the plume as a function of height for the different cases. 


\section{TABLE CAPTIONS}

Table 1. Summary of the models used in the study.

Table 2. Empirical relationships used in this comparison. Unless otherwise noted, the units for all parameters are in SI.

Table 3. Volcanic input parameters for simulations.

Table 4. Values of common parameters. Volcanic gas is assumed to be pure $\mathrm{H}_{2} \mathrm{O}$. Input values are based on properties of the Pinatubo and Shinmoe-dake eruptions compiled for earlier modelling studies (Koyaguchi and Tokuno, 1993; Costa et al., 2013; Suzuki and Koyaguchi, 2013).

Table 5. Summary of the four modelling exercises used to simulate the strong plume and weak plume eruption scenarios.

Table 6. Results for the weak plume case for a fixed MER without wind effects. Heights are above the crater level.

Table 7. Results for the weak plume case for a fixed column height without wind effects. Heights are above the crater level.

Table 8. Results for the weak plume case for a fixed MER with wind effects.

Heights are above the crater level.

Table 9. Results for the weak plume case for a fixed column height with wind effects. Heights are above the crater level. 
Table 10. Results for the strong plume case for a fixed MER without wind effects.

Heights are above the crater level.

Table 11. Results for the strong plume case for a fixed column height without wind effects. Heights are above the crater level.

Table 12. Results for the strong plume case for a fixed MER with wind effects.

Heights are above the crater level.

Table 13. Results for the strong plume case for a fixed column height with wind effects. Heights are above the crater level. 
Table 1. Summary of the models used in the exercise.

\begin{tabular}{|c|c|c|c|c|c|c|c|c|c|c|}
\hline $\begin{array}{l}\text { L } \\
\text { a } \\
\text { b } \\
\text { e } \\
\text { l }\end{array}$ & Name & $\begin{array}{l}\text { Corr. } \\
\text { author }\end{array}$ & $\begin{array}{l}\text { Model } \\
\text { type }\end{array}$ & $\begin{array}{l}\text { Air } \\
\text { entrainment }\end{array}$ & Wind & $\begin{array}{l}\text { Particle } \\
\text { fallout }\end{array}$ & $\begin{array}{l}\text { Particle } \\
\text { re- } \\
\text { entrain. }\end{array}$ & $\begin{array}{l}\text { Moisture } \\
\text { entrain. }\end{array}$ & $\begin{array}{l}\text { Water } \\
\text { latent } \\
\text { heat }\end{array}$ & Ref \\
\hline 1 & Puffin & $\begin{array}{l}\text { M. } \\
\text { Bursik }\end{array}$ & $1 \mathrm{D}$ & $\begin{array}{l}\alpha=0.15 \\
\beta=1.0\end{array}$ & Yes & Yes & Yes & No & No & 1 \\
\hline 2 & Degruyter & $\begin{array}{l}\text { W. } \\
\text { Degruyter }\end{array}$ & $1 \mathrm{D}$ & $\begin{array}{l}\alpha=0.1 \\
\beta=0.5\end{array}$ & Yes & No & No & Yes & Yes & 2 \\
\hline 3 & PlumeMoM & $\begin{array}{l}\text { M. } \\
\text { de'Michie } \\
\text { li }\end{array}$ & $1 \mathrm{D}$ & $\begin{array}{l}\alpha=0.09 \\
\beta=0.6\end{array}$ & Yes & Yes & No & No & No & 3 \\
\hline 4 & Devenish & $\begin{array}{l}\text { B. } \\
\text { Devenish }\end{array}$ & $1 \mathrm{D}$ & $\begin{array}{l}\alpha=0.1 \\
\beta=0.5\end{array}$ & Yes & No & No & Yes & Yes & 4 \\
\hline 5 & FPluMe & $\begin{array}{l}\text { A. } \\
\text { Folch }\end{array}$ & $1 \mathrm{D}$ & $\begin{array}{l}\alpha=f(R i) \\
\beta=g(R i)\end{array}$ & Yes & Yes & Yes & Yes & Yes & 5 \\
\hline 6 & $P P M$ & $\begin{array}{l}\text { F. } \\
\text { Girault }\end{array}$ & $1 \mathrm{D}$ & $\begin{array}{l}\alpha=f(R i) \\
\beta=0.5\end{array}$ & Yes & Yes & No & No & No & 6 \\
\hline 7 & Plumeria & $\begin{array}{l}\text { L. } \\
\text { Mastin }\end{array}$ & $1 \mathrm{D}$ & $\begin{array}{l}\alpha=0.09 \\
\beta=0.5\end{array}$ & Yes & No & No & Yes & Yes & 7 \\
\hline 8 & PlumeRise & $\begin{array}{l}\text { M. } \\
\text { Woodhou } \\
\text { se }\end{array}$ & $1 \mathrm{D}$ & $\begin{array}{l}\alpha=0.09 \\
\beta=0.9\end{array}$ & Yes & No & No & Yes & Yes & 8 \\
\hline 9 & $\overline{A S H 1 D}$ & $\begin{array}{l}\text { M. } \\
\text { Cerminara }\end{array}$ & 1D & $\begin{array}{l}\alpha=0.1 \\
\beta=0.0\end{array}$ & No & No & No & No & Yes & 9 \\
\hline 10 & $\overline{A T H A M}$ & $\begin{array}{l}\text { M. } \\
\text { Herzog }\end{array}$ & $3 \mathrm{D}$ & LES & Yes & Yes & Yes & Yes & Yes & 10 \\
\hline 11 & $S K-3 D$ & $\begin{array}{l}\text { Y. J. } \\
\text { Suzuki }\end{array}$ & $3 \mathrm{D}$ & DNS-LES* & Yes & No & No & No & No & 11 \\
\hline 12 & ASHEE & $\begin{array}{l}\text { M. } \\
\text { Cerminara }\end{array}$ & $3 \mathrm{D}$ & LES & No & Yes & Yes & Yes & Yes & 12 \\
\hline 13 & $P D A C$ & $\begin{array}{l}\text { T. } \\
\text { Esposti } \\
\text { Ongaro }\end{array}$ & $3 \mathrm{D}$ & LES & No & Yes & Yes & No & No & 13 \\
\hline
\end{tabular}

Refs: 1- Bursik (2001), Pouget et al. (this issue); 2- Degruyter and Bonadonna (2012); 3- de' Michieli Vitturi et al. (2015; this issue); 4- Devenish (2013; this issue); 5- Folch et al. (2015), Macedonio et al. (this issue), Folch et al. (2015); 6- Girault et al. (2014; this issue); 7- Mastin (2007; 2014; this issue); 8Woodhouse et al. (2013; this issue); 9- Cerminara (2015); 10- Herzog et al. (1998; this issue); 11 Suzuki and Koyaguchi (2009), Suzuki et al. (this issue-a); 12- Cerminara et al. (2015), Cerminara and Esposti Ongaro (this issue); 13- Ongaro et al. (2007), Esposti Ongaro (this issue); *- see the description of SK-3D in Section 2.3. 
Table 2: Empirical relationships between plume height above vent $(H)$ and mass eruption rate $(\dot{M})$ used in this comparison. Unless otherwise noted, the units for all parameters are in SI.

\begin{tabular}{|c|c|c|}
\hline Study & Relationship & Parameters \\
\hline $\begin{array}{l}\text { Carazzo et al. } \\
(2014) \\
(\text { eqs. } 7-10)\end{array}$ & $\begin{array}{l}\ln (\dot{M})=\ln \left(b_{1} H^{n_{1}}\right)+c W H \quad\left(H \leq H_{1}\right) \\
\ln (\dot{M})=\ln \left(b_{2} H^{n_{2}}\right)+c W H\left(H_{1}<H \leq H_{2}\right) \\
\ln (\dot{M})=\ln \left(b_{3} H^{n_{3}}\right)+c W H\left(H_{2}<H \leq H_{3}\right) \\
\ln (\dot{M})=\ln \left(b_{4} H^{n_{4}}\right)+c W H\left(H>H_{3}\right) \\
\text { For strong plume: } b_{4}, c, n_{4} \text { for tropics, and } W=17.89 \mathrm{~m} \mathrm{~s}^{-1} \\
\text { For weak plume: } b_{1}, c, n_{1} \text { for mid-latitudes, and } W=83.66 \mathrm{~m} \\
\quad \mathrm{~s}^{-1}\end{array}$ & $\begin{array}{l}\text { Polar atmosphere: } \\
b_{1}, b_{2}, b_{3}, b_{4}=142.14,2.21,46.73,1928.8 ; \\
c=0.0031 ; H_{1}, H_{2}, H_{3}=10,14,20 \mathrm{~km} ; \\
n_{1}, n_{2}, n_{3}, n_{4}=4.04,5.86,4.72,3.47 \\
\text { Mid-latitudes: } \\
b_{1}, b_{2}, b_{3}, b_{4}=63.22,0.061,4.41,653.81 ; \\
c=0.0025 ; H_{1}, H_{2}, H_{3}=11.5,17,21 \mathrm{~km} ; \\
n_{1}, n_{2}, n_{3}, n_{4}=4.06,6.89,5.38,3.75 \\
\text { Tropics: } \\
b_{1}, b_{2}, b_{3}, b_{4}=59.61,0.0014,0.198,429.2 ; \\
c=0.0016 ; \\
H_{1}, H_{2}, H_{3}=17,21,26 \mathrm{~km} ; \\
n_{1}, n_{2}, n_{3}, n_{4}=4.05,7.78,6.18,3.84\end{array}$ \\
\hline $\begin{array}{l}\text { Degruyter and } \\
\text { Bonadonna } \\
(2012)\end{array}$ & $\begin{array}{l}\dot{M}=\pi \frac{\rho_{a 0}}{g^{\prime}}\left(\frac{2^{5 / 2} \alpha^{2} \bar{N}^{3}}{z_{l}^{4}} H^{4}+\frac{\beta^{2} \bar{N}^{2} \bar{v}}{6} H^{3}\right) \\
g^{\prime}=g\left(\frac{c_{0} \theta_{0}-c_{a 0} \theta_{a 0}}{c_{a 0} \theta_{a 0}}\right) \\
\text { For strong plume: } \theta_{0}=1053 \mathrm{~K}, H=37000 \mathrm{~m}, \theta_{a 0}=290.5 \mathrm{~K}, \\
\quad \rho_{a 0}=1.012 \mathrm{~kg} / \mathrm{m}^{3}, g^{\prime}=29.296, \bar{N}=0.0172, \bar{v}=11.8135 \mathrm{~m} \mathrm{~s}^{-} \\
\text {For weak plume: } \theta_{0}=1273 \mathrm{~K}, H=6000 \mathrm{~m}, \theta_{\mathrm{a} 0}=268.7 \mathrm{~K}, \\
\quad \rho_{a 0}=1.105 \mathrm{~kg} / \mathrm{m}^{3}, g^{\prime}=41.289, \bar{N}=0.0134, \bar{v}=31.3935 \mathrm{~m} \mathrm{~s}^{-} \\
\text {For both cases: } \alpha=0.1, \beta=0.5, z_{1}=2.8, c_{0}=1100 \mathrm{~J} /(\mathrm{kg} \mathrm{K}), \\
\quad c_{a 0}=1000 \mathrm{~J} /(\mathrm{kg} \mathrm{K})\end{array}$ & $\begin{array}{l}c_{0}=\text { source specific heat } \\
c_{a 0}=\text { specific heat of the atmosphere } \\
g=\text { gravitational constant }=9.81 \mathrm{~m} \mathrm{~s}^{-2} \\
g^{\prime}=\text { reduced gravity } \\
\bar{N}=\text { average buoyancy frequency } \\
\bar{v}=\text { average wind velocity } \\
Z_{l}=\text { Max. non-dimensional height } \\
\alpha, \beta=\text { radial and crossflow entrainment } \\
\quad \text { coefficients } \\
\theta_{0}=\text { source temperature } \\
\theta_{a 0}=\text { atmospheric temperature }\end{array}$ \\
\hline $\begin{array}{l}\text { Mastin et al. } \\
\text { (2009) (eq. 1) }\end{array}$ & $M=\rho_{m}(H / 2)^{4.15} ; \quad \rho_{m}=2500 \mathrm{~kg} \mathrm{~m}^{-3}$ & $\rho_{\mathrm{m}}=$ magma density \\
\hline $\begin{array}{l}\text { Woodhouse et } \\
\text { al. (2013); } \\
\text { Woodhouse et } \\
\text { al. (2016) }\end{array}$ & $\begin{array}{l}M=0.35{ }^{2} f\left(W_{s}\right)^{4} \frac{a 0}{g^{\prime}} N^{3} H^{4} \\
f\left(W_{s}\right)=\frac{1+1.4266 W_{s}+0.3527 W_{s}^{2}}{1+1.373 W_{s}} \\
W_{s}=1.44 \dot{\gamma} / N \\
g^{\prime}=g \frac{\left(C_{v} n_{0}+C_{s}\left(\begin{array}{ll}1 & n_{0}\end{array}\right)\right) \quad C_{A} \quad A 0}{C_{A} \quad A 0} \\
\text { For strong plume: } \theta_{0}=1053 \mathrm{~K}, n_{0}=0.05, H=37000 \mathrm{~m}, \\
\quad \theta_{a 0}=290.5 \mathrm{~K}, \rho_{a 0}=1.011 \mathrm{~kg} / \mathrm{m}^{3}, N=0.019 \mathrm{~s}^{-1}, \dot{\gamma}=0.0003 \mathrm{~s}^{-1} \\
\text { For weak plume }: \theta_{0}=1273 \mathrm{~K}, n_{0}=0.03, H=6000 \mathrm{~m}, \theta_{\mathrm{a} 0}=268.8 \\
\mathrm{~K}, \rho_{a 0}=1.104 \mathrm{~kg} / \mathrm{m}^{3}, N=0.014 \mathrm{~s}^{-1}, \dot{\gamma}=0.007 \mathrm{~s}^{-1} \\
\text { For both cases: } \alpha=0.09, C_{s}=1100 \mathrm{~J} /(\mathrm{kg} \mathrm{K}), C_{v}=1810 \mathrm{~J} /(\mathrm{kg} \\
\mathrm{K}), C_{a}=1000 \mathrm{~J} /(\mathrm{kg} \mathrm{K})\end{array}$ & $\begin{array}{l}W_{s}=\text { dimensionless wind strength } \\
N=\text { buoyancy frequency } \\
\dot{\gamma}=\text { shear rate of atmospheric wind } \\
C_{V}=\text { specific heat of water vapor } \\
\mathrm{C}_{\mathrm{s}}=\text { specific heat of solids } \\
C_{a}=\text { specific heat of dry air } \\
g=\text { gravitational constant }=9.81 \mathrm{~m} \mathrm{~s}^{-2} \\
g^{\prime}=\text { reduced gravity }\end{array}$ \\
\hline
\end{tabular}


Table 3. Volcanic input parameters for simulations.

\begin{tabular}{|l|l|l|}
\hline Parameter & Weak plume & Strong plume \\
\hline Vent elevation & $1500 \mathrm{~m}$ & $1500 \mathrm{~m}$ \\
\hline Eruption duration & $0.2 \mathrm{hours}$ & 2.5 hours \\
\hline Mass eruption rate & $1.5 \times 10^{6} \mathrm{~kg} / \mathrm{s}$ & $1.5 \times 10^{9} \mathrm{~kg} / \mathrm{s}$ \\
\hline Eruption column height & $6000 \mathrm{~m}($ above vent $)$ & $37000 \mathrm{~m}($ above vent $)$ \\
\hline Exit velocity & $135 \mathrm{~m} / \mathrm{s}$ & $275 \mathrm{~m} / \mathrm{s}$ \\
\hline Exit temperature & $1273 \mathrm{~K}$ & $1053 \mathrm{~K}$ \\
\hline Exit water fraction & $3 \mathrm{wt} \%$ & $5 \mathrm{wt} \%$ \\
\hline $\begin{array}{l}\text { Particle size distribution } \\
\text { and density }\end{array}$ & $\Phi_{c}=0 ; \rho=2200 \mathrm{~kg} / \mathrm{m}^{3}$ & $\Phi_{c}=1 ; \rho=2500 \mathrm{~kg} / \mathrm{m}^{3}$ \\
\hline
\end{tabular}

Table 4. Values of common parameters. Volcanic gas is assumed to be pure $\mathrm{H}_{2} \mathrm{O}$. Input values are based on properties of the Pinatubo and Shinmoe-dake eruptions compiled for earlier modeling studies (Koyaguchi and Tokuno, 1993; Costa et al., 2013; Suzuki and Koyaguchi, 2013).

\begin{tabular}{|l|l|}
\hline Parameter & Value \\
\hline Specific heat of solid pyroclasts & $1100 \mathrm{~J} \mathrm{~kg}^{-1} \mathrm{~K}^{-1}$ \\
\hline Specific heat of water vapor at constant volume & $1348 \mathrm{~J} \mathrm{~kg}^{-1} \mathrm{~K}^{-1}$ \\
\hline Specific heat of air at constant volume & $717 \mathrm{~J} \mathrm{~kg}^{-1} \mathrm{~K}^{-1}$ \\
\hline Specific heat of water vapor at constant pressure & $1810 \mathrm{~J} \mathrm{~kg}^{-1} \mathrm{~K}^{-1}$ \\
\hline Specific heat of air at constant pressure & $1000 \mathrm{~J} \mathrm{~kg}^{-1} \mathrm{~K}^{-1}$ \\
\hline Gas constant of water & $462 \mathrm{~J} \mathrm{~kg}^{-1} \mathrm{~K}^{-1}$ \\
\hline Gas constant of air & $287 \mathrm{~J} \mathrm{~kg}^{-1} \mathrm{~K}^{-1}$ \\
\hline Gravitational acceleration & $9.80665 \mathrm{~m} \mathrm{~s}^{-2}$ \\
\hline
\end{tabular}

Table 5. Summary of the four modeling exercises used to simulate the strong plume and weak plume eruption scenarios.

\begin{tabular}{llllll}
\hline Exercise & Wind effects & Approach & Fixed value & Weak plume & Strong plume \\
\hline 1 & No & Forward & MER & WP1 & SP1 \\
2 & No & Inverse & Height & WP2 & SP2 \\
3 & Yes & Forward & MER & WP3 & SP3 \\
4 & Yes & Inverse & Height & WP4 & SP4 \\
\hline
\end{tabular}


Table 6. Results for the weak plume case for a fixed MER without wind effects. Heights are above the crater level.

\begin{tabular}{|l|l|l|l|l|}
\hline Model & Label & Height $(\mathrm{m})$ & $N B L(\mathrm{~m})$ & $M E R\left(\mathrm{~kg} \mathrm{~s}^{-1}\right)$ \\
\hline Puffin & 1 & 8795.2 & 6836.8 & $1.49 \mathrm{E}+6$ \\
\hline Degruyter & 2 & 8885.7 & 6833.6 & $1.50 \mathrm{E}+6$ \\
\hline PlumeMom & 3 & 8836.0 & 6760.0 & $1.50 \mathrm{E}+6$ \\
\hline Devenish & 4 & 8508.9 & 6458.0 & $1.50 \mathrm{E}+6$ \\
\hline FPlume & 5 & 8378.0 & 6130.0 & $1.50 \mathrm{E}+6$ \\
\hline PPM & 6 & 11140.0 & 7770.0 & $1.50 \mathrm{E}+6$ \\
\hline Plumeria & 7 & 9217.0 & 6948.0 & $1.50 \mathrm{E}+6$ \\
\hline PlumeRise & 8 & 9154.0 & 6902.0 & $1.50 \mathrm{E}+6$ \\
\hline Dusty-1D & 9 & 8358.6 & 6186.0 & $1.50 \mathrm{E}+6$ \\
\hline ATHAM & 10 & 16111.0 & 5660.0 & $1.50 \mathrm{E}+6$ \\
\hline SK-3D & 11 & 11070.0 & 6940.0 & $1.50 \mathrm{E}+6$ \\
\hline ASHEE & 12 & 10380.0 & 6760.0 & $1.50 \mathrm{E}+6$ \\
\hline PDAC & 13 & 11000.0 & 7850.0 & $1.50 \mathrm{E}+6$ \\
\hline $\begin{array}{l}\text { Average } \\
\text { (standard deviation \%) }\end{array}$ & $\mathbf{0}$ & $\begin{array}{l}\mathbf{9 9 8 7 . 3} \\
(\mathbf{2 1 . 2 \% )}\end{array}$ & $\begin{array}{l}\mathbf{6 7 7 1 . 9} \\
\mathbf{( 8 . 9 \% )}\end{array}$ & $\mathbf{1 . 5 0 E + 6}$ \\
\hline $\begin{array}{l}\text { Mastin et al. (2009) } \\
\text { (\% difference with average) }\end{array}$ & 14 & $\begin{array}{l}9344.7 \\
(-6.4 \%)\end{array}$ & - & $1.50 \mathrm{E}+6$ \\
\hline $\begin{array}{l}\text { Degruyter \& Bonadonna (2012) } \\
\text { (\% difference with average) }\end{array}$ & 15 & $\begin{array}{l}9246.0 \\
(-7.4 \%)\end{array}$ & - & $1.50 \mathrm{E}+6$ \\
\hline $\begin{array}{l}\text { Woodhouse et al. (this issue) } \\
\text { (\% difference with average) }\end{array}$ & 16 & $\begin{array}{l}9197.8 \\
(-7.9 \%)\end{array}$ & - & $1.50 \mathrm{E}+6$ \\
\hline $\begin{array}{l}\text { Carazzo et al. (2014) } \\
\text { (\% difference with average) }\end{array}$ & 17 & $\begin{array}{l}11950.0 \\
(19.7 \%)\end{array}$ & & $1.50 \mathrm{E}+6$ \\
\hline
\end{tabular}

Table 7. Results for the weak plume case for a fixed column height without wind effects. Heights are above the crater level.

\begin{tabular}{|l|l|l|l|l|}
\hline Model & Label & Height $(\mathrm{m})$ & NBL $(\mathrm{m})$ & $M E R\left(\mathrm{~kg} \mathrm{~s}^{-1}\right)$ \\
\hline Puffin & 1 & 5834.7 & 3979.1 & $1.65 \mathrm{E}+5$ \\
\hline Degruyter & 2 & 6000.0 & 4260.0 & $2.14 \mathrm{E}+5$ \\
\hline PlumeMom & 3 & 6000.0 & 4230.0 & $2.09 \mathrm{E}+5$ \\
\hline Devenish & 4 & 6000.0 & 4218.1 & $2.66 \mathrm{E}+5$ \\
\hline FPlume & 5 & 5993.0 & 4400.0 & $6.31 \mathrm{E}+5$ \\
\hline PPM & 6 & 6000.0 & 4150.0 & $1.20 \mathrm{E}+5$ \\
\hline Plumeria & 7 & 6000.0 & 4204.0 & $1.87 \mathrm{E}+5$ \\
\hline PlumeRise & 8 & 6000.0 & 4234.0 & $1.94 \mathrm{E}+5$ \\
\hline Dusty-1D & 9 & 6000.0 & 4424.0 & $3.92 \mathrm{E}+5$ \\
\hline $\begin{array}{l}\text { Average } \\
\text { (standard deviation \%) }\end{array}$ & $\mathbf{0}$ & $\mathbf{5 9 8 0 . 9}$ & $\begin{array}{l}\mathbf{4 2 3 3 . 2} \\
\mathbf{( 3 . 1 \% )}\end{array}$ & $\begin{array}{l}\mathbf{2 . 6 4 E + 5} \\
(\mathbf{5 9 . 5} \%)\end{array}$ \\
\hline $\begin{array}{l}\text { Mastin et al. (2009) } \\
\text { (\% difference with average) }\end{array}$ & 14 & 6000.0 & - & $\begin{array}{l}2.39 \mathrm{E}+5 \\
(-9.7 \%)\end{array}$ \\
\hline $\begin{array}{l}\text { Degruyter \& Bonadonna (2012) } \\
\text { (\% difference with average) }\end{array}$ & 15 & 6000.0 & - & $\begin{array}{l}2.08 \mathrm{E}+5 \\
(-21.3 \%)\end{array}$ \\
\hline $\begin{array}{l}\text { Woodhouse et al. (this issue) } \\
\text { (\% difference with average) }\end{array}$ & 16 & 6000.0 & - & $\begin{array}{l}2.72 \mathrm{E}+5 \\
(2.9 \%)\end{array}$ \\
\hline $\begin{array}{l}\text { Carazzo et al. (2014) } \\
\text { (\% difference with average) }\end{array}$ & 17 & 6000.0 & & $\begin{array}{l}9.12 \mathrm{E}+4 \\
(-65.5 \%)\end{array}$ \\
\hline
\end{tabular}


Table 8. Results for the weak plume case for a fixed MER with wind effects. Heights are above the crater level.

\begin{tabular}{|l|l|l|l|l|}
\hline Model & Label & Height $(\mathrm{m})$ & $N B L(\mathrm{~m})$ & $M E R\left(\mathrm{~kg} \mathrm{~s}^{-1}\right)$ \\
\hline Puffin & 1 & 2133.6 & 1874.8 & $1.49 \mathrm{E}+6$ \\
\hline Degruyter & 2 & 4395.4 & 3483.8 & $1.50 \mathrm{E}+6$ \\
\hline PlumeMom & 3 & 3929.6 & 3139.0 & $1.50 \mathrm{E}+6$ \\
\hline Devenish & 4 & 4514.1 & 3570.0 & $1.50 \mathrm{E}+6$ \\
\hline FPlume & 5 & 4556.0 & 3235.0 & $1.50 \mathrm{E}+6$ \\
\hline PPM & 6 & 4050.0 & 4050.0 & $1.50 \mathrm{E}+6$ \\
\hline Plumeria & 7 & 4721.0 & 3727.0 & $1.50 \mathrm{E}+6$ \\
\hline PlumeRise & 8 & 3273.5 & 2696.0 & $1.50 \mathrm{E}+6$ \\
\hline ATHAM & 10 & 5516.0 & 3800.0 & $1.50 \mathrm{E}+6$ \\
\hline SK-3D & 11 & 6470.0 & 3480.0 & $1.50 \mathrm{E}+6$ \\
\hline $\begin{array}{l}\text { Average } \\
\text { (standard deviation \%) }\end{array}$ & $\mathbf{0}$ & $\begin{array}{l}\mathbf{4 3 5 5 . 9} \\
(\mathbf{2 6 . 9 \%})\end{array}$ & $\begin{array}{l}\mathbf{3 3 0 5 . 6} \\
\mathbf{( 1 9 . 0 \% )}\end{array}$ & $\mathbf{1 . 5 0 E + 6}$ \\
\hline $\begin{array}{l}\text { Mastin et al. (2009) } \\
\text { (\% difference with average) }\end{array}$ & 14 & $\begin{array}{l}9344.7 \\
(114.5 \%)\end{array}$ & - & $1.50 \mathrm{E}+6$ \\
\hline $\begin{array}{l}\text { Degruyter \& Bonadonna (2012) } \\
\text { (\% difference with average) }\end{array}$ & 15 & $\begin{array}{l}4453.0 \\
(2.2 \%)\end{array}$ & - & $1.50 \mathrm{E}+6$ \\
\hline $\begin{array}{l}\text { Woodhouse et al. (this issue) } \\
\text { (\% difference with average) }\end{array}$ & 16 & $\begin{array}{l}4324.0 \\
(-0.7 \%)\end{array}$ & - & $1.50 \mathrm{E}+6$ \\
\hline $\begin{array}{l}\text { Carazzo et al. (2014) } \\
\text { (\% difference with average) }\end{array}$ & 17 & $\begin{array}{l}7940.0 \\
(82.3 \%)\end{array}$ & & $1.50 \mathrm{E}+6$ \\
\hline
\end{tabular}

Table 9. Results for the weak plume case for a fixed column height with wind effects. Heights are above the crater level.

\begin{tabular}{|c|c|c|c|c|}
\hline Model & Label & Height $(\mathrm{m})$ & $N B L(\mathrm{~m})$ & $\operatorname{MER}\left(\mathrm{kg} \mathrm{s}^{-1}\right)$ \\
\hline Puffin & 1 & 6078.0 & 5250.0 & $2.04 \mathrm{E}+7$ \\
\hline Degruyter & 2 & 6000.0 & 4662.5 & $3.72 \mathrm{E}+6$ \\
\hline PlumeMom & 3 & 6000.0 & 4583.0 & $5.40 \mathrm{E}+6$ \\
\hline Devenish & 4 & 5998.0 & 4663.7 & $8.28 E+5$ \\
\hline FPlume & 5 & 5991.0 & 4196.0 & $3.77 \mathrm{E}+6$ \\
\hline PPM & 6 & 6000.0 & 6000.0 & $4.94 \mathrm{E}+6$ \\
\hline Plumeria & 7 & 6000.0 & 4736.0 & $2.87 \mathrm{E}+6$ \\
\hline PlumeRise & 8 & 6000.0 & 4740.0 & $1.08 \mathrm{E}+7$ \\
\hline $\begin{array}{l}\text { Average } \\
\text { (standard deviation \%) }\end{array}$ & 0 & 6008.4 & $\begin{array}{l}4853.9 \\
(11.2 \%)\end{array}$ & $\begin{array}{l}6.60 \mathrm{E}+6 \\
(95.3 \%)\end{array}$ \\
\hline $\begin{array}{l}\text { Mastin et al. (2009) } \\
\text { (\% difference with average) }\end{array}$ & 14 & 6000.0 & - & $\begin{array}{l}2.39 \mathrm{E}+5 \\
(-96.4 \%)\end{array}$ \\
\hline $\begin{array}{l}\text { Degruyter \& Bonadonna (2012) } \\
\text { (\% difference with average) }\end{array}$ & 15 & 6000.0 & - & $\begin{array}{l}4.07 \mathrm{E}+6 \\
(-38.3 \%)\end{array}$ \\
\hline $\begin{array}{l}\text { Woodhouse et al. (this issue) } \\
\text { (\% difference with average) }\end{array}$ & 16 & 6000.0 & - & $\begin{array}{l}5.56 \mathrm{E}+6 \\
(-15.7 \%)\end{array}$ \\
\hline $\begin{array}{l}\text { Carazzo et al. (2014) } \\
\text { (\% difference with average) }\end{array}$ & 17 & 6000.0 & & $\begin{array}{l}3.20 \mathrm{E}+5 \\
(-95.1 \%)\end{array}$ \\
\hline
\end{tabular}


Table 10. Results for the strong plume case for a fixed MER without wind effects. Heights are above the crater level.

\begin{tabular}{|l|l|l|l|l|}
\hline Model & Label & Height $(\mathrm{m})$ & NBL $(\mathrm{m})$ & MER $\left(\mathrm{kg} \mathrm{s}^{-1}\right)$ \\
\hline Puffin & 1 & 34781.8 & 23286.5 & $1.50 \mathrm{E}+9$ \\
\hline Degruyter & 2 & 42257.7 & 27868.0 & $1.50 \mathrm{E}+9$ \\
\hline PlumeMom & 3 & 38598.0 & 24535.0 & $1.50 \mathrm{E}+9$ \\
\hline Devenish & 4 & 36620.0 & 23226.0 & $1.50 \mathrm{E}+9$ \\
\hline FPlume & 5 & 41083.0 & 25460.0 & $1.50 \mathrm{E}+9$ \\
\hline PPM & 6 & 41520.0 & 28260.0 & $1.50 \mathrm{E}+9$ \\
\hline Plumeria & 7 & 39989.0 & 24858.0 & $1.50 \mathrm{E}+9$ \\
\hline PlumeRise & 8 & 41052.0 & 26062.0 & $1.50 \mathrm{E}+9$ \\
\hline Dusty-1D & 9 & 37101.0 & 24040.0 & $1.50 \mathrm{E}+9$ \\
\hline ATHAM & 10 & 33392.0 & 16230.0 & $1.50 \mathrm{E}+9$ \\
\hline SK-3D & 11 & 39920.0 & 20000.0 & $1.50 \mathrm{E}+9$ \\
\hline ASHEE & 12 & 36700.0 & 22100.0 & $1.50 \mathrm{E}+9$ \\
\hline PDAC & 13 & 42500.0 & 28500.0 & $1.50 \mathrm{E}+9$ \\
\hline $\begin{array}{l}\text { Average } \\
\text { (standard deviation \%) }\end{array}$ & $\mathbf{0}$ & $\begin{array}{l}\mathbf{3 8 8 8 5 . 7} \\
\mathbf{( 7 . 5 \% )}\end{array}$ & $\mathbf{2 4 1 8 6 . 6}$ & $\mathbf{1 . 5 0 E + 9}$ \\
\hline $\begin{array}{l}\text { Mastin et al. (2009) } \\
\text { (\% difference with average) }\end{array}$ & 14 & $\begin{array}{l}49381.5 \\
(27.0 \%)\end{array}$ & - & $1.50 \mathrm{E}+9$ \\
\hline $\begin{array}{l}\text { Degruyter \& Bonadonna (2012) } \\
\text { (\% difference with average) }\end{array}$ & 15 & $\begin{array}{l}42245.0 \\
(8.6 \%)\end{array}$ & - & $1.50 \mathrm{E}+9$ \\
\hline $\begin{array}{l}\text { Woodhouse et al. (this issue) } \\
\text { (\% difference with average) }\end{array}$ & 16 & $\begin{array}{l}38638.0 \\
(-0.6 \%)\end{array}$ & - & $1.50 \mathrm{E}+9$ \\
\hline $\begin{array}{l}\text { Carazzo et al. (2014) } \\
\text { (\% difference with average) }\end{array}$ & 17 & $\begin{array}{l}50600.0 \\
(30.1 \%)\end{array}$ & & $1.50 \mathrm{E}+9$ \\
\hline
\end{tabular}

Table 11. Results for the strong plume case for a fixed column height without wind effects. Heights are above the crater level.

\begin{tabular}{|l|l|l|l|l|}
\hline Model & Label & Height $(\mathrm{m})$ & NBL $(\mathrm{m})$ & $M E R\left(\mathrm{~kg} \mathrm{~s}^{-1}\right)$ \\
\hline Puffin & 1 & 37068.0 & 24598.1 & $2.11 \mathrm{E}+9$ \\
\hline Degruyter & 2 & 37000.0 & 24800.0 & $8.23 \mathrm{E}+8$ \\
\hline PlumeMom & 3 & 37003.0 & 23970.0 & $1.26 \mathrm{E}+9$ \\
\hline Devenish & 4 & 37000.0 & 23560.7 & $1.60 \mathrm{E}+9$ \\
\hline FPlume & 5 & 36999.0 & 23400.0 & $1.00 \mathrm{E}+9$ \\
\hline PPM & 6 & 37000.0 & 25740.0 & $3.15 \mathrm{E}+8$ \\
\hline Plumeria & 7 & 37000.0 & 23101.0 & $9.28 \mathrm{E}+8$ \\
\hline PlumeRise & 8 & 37000.0 & 23686.0 & $8.71 \mathrm{E}+8$ \\
\hline Dusty-1D & 9 & 37000.0 & 23770.0 & $1.41 \mathrm{E}+9$ \\
\hline $\begin{array}{l}\text { Average } \\
\text { (standard deviation \%) }\end{array}$ & $\mathbf{0}$ & $\mathbf{3 7 0 0 7 . 8}$ & $\mathbf{2 4 0 6 9 . 5}$ & $\begin{array}{l}\mathbf{1 . 1 5 E}+9 \\
\mathbf{( 4 7 . 5 \% )}\end{array}$ \\
\hline $\begin{array}{l}\text { Mastin et al. (2009) } \\
\text { (\% difference with average) }\end{array}$ & 14 & 37000.0 & - & $\begin{array}{l}4.53 \mathrm{E}+8 \\
(-60.5 \%)\end{array}$ \\
\hline $\begin{array}{l}\text { Degruyter \& Bonadonna (2012) } \\
\text { (\% difference with average) }\end{array}$ & 15 & 37000.0 & - & $\begin{array}{l}8.19 \mathrm{E}+8 \\
(-28.5 \%)\end{array}$ \\
\hline $\begin{array}{l}\text { Woodhouse et al. (this issue) } \\
\text { (\% difference with average) }\end{array}$ & 16 & 37000.0 & - & $\begin{array}{l}1.26 \mathrm{E}+.9 \\
(9.9 \%)\end{array}$ \\
\hline $\begin{array}{l}\text { Carazzo et al. (2014) } \\
\text { (\% difference with average) }\end{array}$ & 17 & 37000.0 & & $\begin{array}{l}4.51 \mathrm{E}+8 \\
(-60.7 \%)\end{array}$ \\
\hline
\end{tabular}


Table 12. Results for the strong plume case for a fixed MER with wind effects. Heights are above the crater level.

\begin{tabular}{|l|l|l|l|l|}
\hline Model & Label & Height $(\mathrm{m})$ & NBL $(\mathrm{m})$ & $M E R\left(\mathrm{~kg} \mathrm{~s}^{-1}\right)$ \\
\hline Puffin & 1 & 31207.2 & 21416.3 & $1.50 \mathrm{E}+9$ \\
\hline Degruyter & 2 & 38779.4 & 25942.0 & $1.50 \mathrm{E}+9$ \\
\hline PlumeMom & 3 & 34626.0 & 22592.0 & $1.50 \mathrm{E}+9$ \\
\hline Devenish & 4 & 35844.3 & 22545.8 & $1.50 \mathrm{E}+9$ \\
\hline FPlume & 5 & 37944.0 & 23082.0 & $1.50 \mathrm{E}+9$ \\
\hline PPM & 6 & 37530.0 & 25360.0 & $1.50 \mathrm{E}+9$ \\
\hline Plumeria & 7 & 38936.0 & 24354.0 & $1.49 \mathrm{E}+9$ \\
\hline PlumeRise & 8 & 35623.0 & 23120.0 & $1.50 \mathrm{E}+9$ \\
\hline ATHAM & 10 & 31955.0 & 15660.0 & $1.50 \mathrm{E}+9$ \\
\hline SK-3D & 11 & 39860.0 & 17913.0 & $1.50 \mathrm{E}+9$ \\
\hline $\begin{array}{l}\text { Average } \\
\text { (standard deviation \%) }\end{array}$ & $\mathbf{0}$ & $\begin{array}{l}\mathbf{3 6 2 3 0 . 5} \\
\mathbf{( 8 . 1 \% )}\end{array}$ & $\mathbf{2 2 1 9 8 . 5}$ & $\mathbf{1 . 5 0 E + 9}$ \\
\hline $\begin{array}{l}\text { Mastin et al. (2009) } \\
\text { (\% difference with average) }\end{array}$ & 14 & $\begin{array}{l}49381.5 \\
(35.8 \%)\end{array}$ & - & $1.50 \mathrm{E}+9$ \\
\hline $\begin{array}{l}\text { Degruyter \& Bonadonna (2012) } \\
\text { (\% difference with average) }\end{array}$ & 15 & $\begin{array}{l}36755.0 \\
(1.1 \%)\end{array}$ & - & $1.50 \mathrm{E}+9$ \\
\hline $\begin{array}{l}\text { Woodhouse et al. (this issue) } \\
\text { (\% difference with average) }\end{array}$ & 16 & $\begin{array}{l}36033.7 \\
(-0.9 \%)\end{array}$ & - & $1.50 \mathrm{E}+9$ \\
\hline $\begin{array}{l}\text { Carazzo et al. (2014) } \\
\text { (\% difference with average) }\end{array}$ & 17 & $\begin{array}{l}38080.0 \\
(6.5 \%)\end{array}$ & & $1.50 \mathrm{E}+9$ \\
\hline
\end{tabular}

Table 13. Results for the strong plume case for a fixed column height with wind effects. Heights are above the crater level.

\begin{tabular}{|l|l|l|l|l|}
\hline Model & Label & Height $(\mathrm{m})$ & NBL $(\mathrm{m})$ & $M E R\left(\mathrm{~kg} \mathrm{~s}^{-1}\right)$ \\
\hline Puffin & 1 & 37001.5 & 24797.6 & $1.62 \mathrm{E}+8$ \\
\hline Degruyter & 2 & 37000.0 & 24909.0 & $1.22 \mathrm{E}+9$ \\
\hline PlumeMom & 3 & 37000.0 & 24107.0 & $2.06 \mathrm{E}+9$ \\
\hline Devenish & 4 & 37000.0 & 23628.2 & $1.83 \mathrm{E}+9$ \\
\hline FPlume & 5 & 36994.0 & 22632.0 & $1.36 \mathrm{E}+9$ \\
\hline PPM & 6 & 37000.0 & 25330.0 & $4.90 \mathrm{E}+8$ \\
\hline Plumeria & 7 & 37000.0 & 23185.0 & $1.09 \mathrm{E}+9$ \\
\hline PlumeRise & 8 & 37000.0 & 23891.0 & $1.81 \mathrm{E}+9$ \\
\hline $\begin{array}{l}\text { Average } \\
\text { (standard deviation \%) }\end{array}$ & $\mathbf{0}$ & $\mathbf{3 6 9 9 9 . 4}$ & $\begin{array}{l}\mathbf{2 4 0 6 0 . 0} \\
\mathbf{( 3 . 8 \% )}\end{array}$ & $\begin{array}{l}\mathbf{1 . 2 5 E}+9 \\
(\mathbf{5 3 . 2 \%})\end{array}$ \\
\hline $\begin{array}{l}\text { Mastin et al. (2009) } \\
\text { (\% difference with average) }\end{array}$ & 14 & 37000.0 & - & $\begin{array}{l}4.53 \mathrm{E}+8 \\
(-63.9 \%)\end{array}$ \\
\hline $\begin{array}{l}\text { Degruyter \& Bonadonna (2012) } \\
\text { (\% difference with average) }\end{array}$ & 15 & 37000.0 & - & $\begin{array}{l}1.54 \mathrm{E}+9 \\
(22.9 \%)\end{array}$ \\
\hline $\begin{array}{l}\text { Woodhouse et al. (this issue) } \\
\text { (\% difference with average) }\end{array}$ & 16 & 37000.0 & - & $\begin{array}{l}1.67 \mathrm{E}+9 \\
(33.3 \%)\end{array}$ \\
\hline $\begin{array}{l}\text { Carazzo et al. (2014) } \\
\text { (\% difference with average) }\end{array}$ & 17 & 37000.0 & & $\begin{array}{l}1.30 \mathrm{E}+9 \\
(3.7 \%)\end{array}$ \\
\hline
\end{tabular}




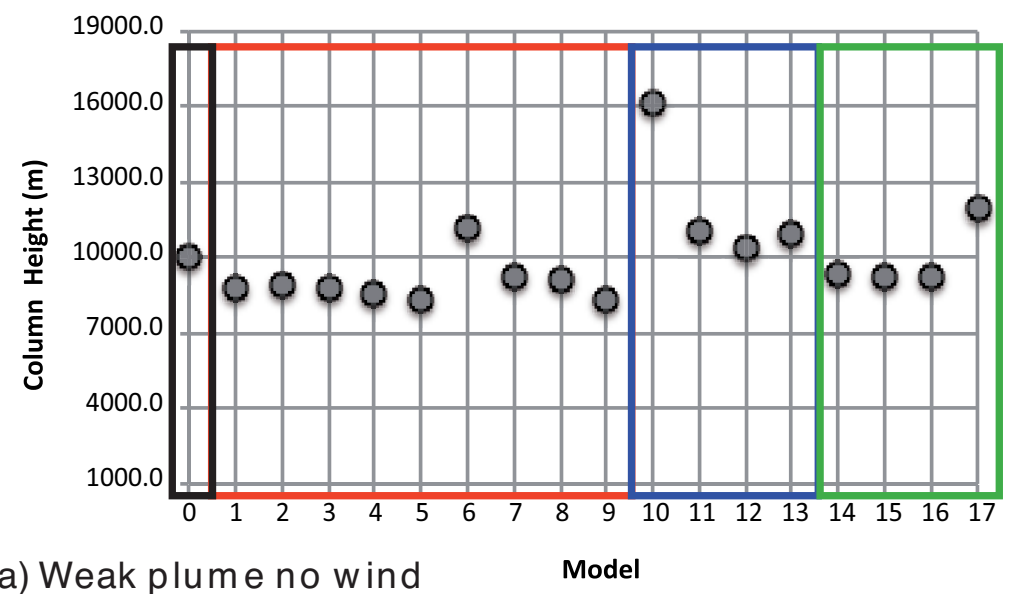

a) Weak plume no wind

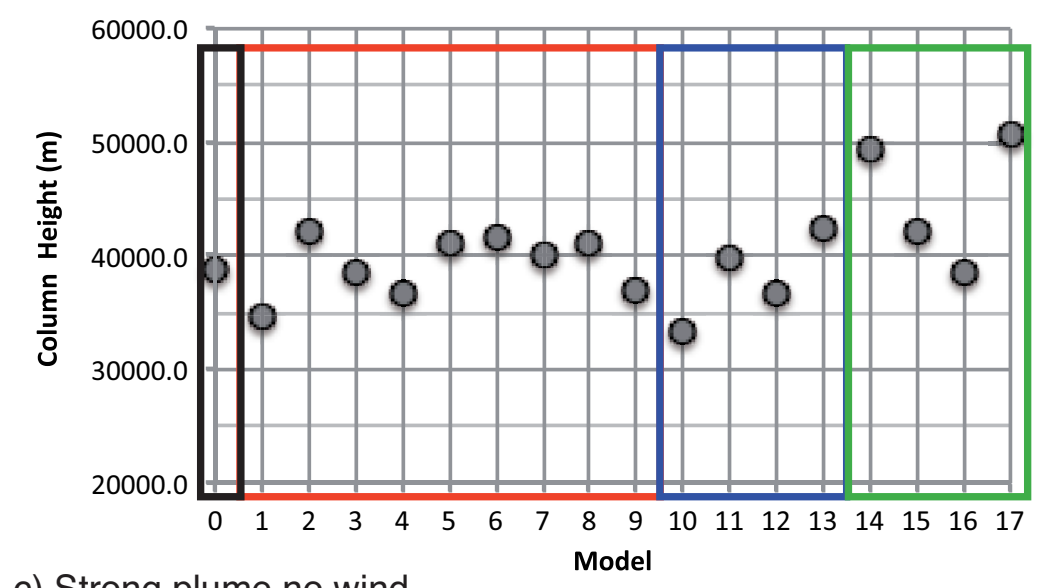

c) Strong plume no wind

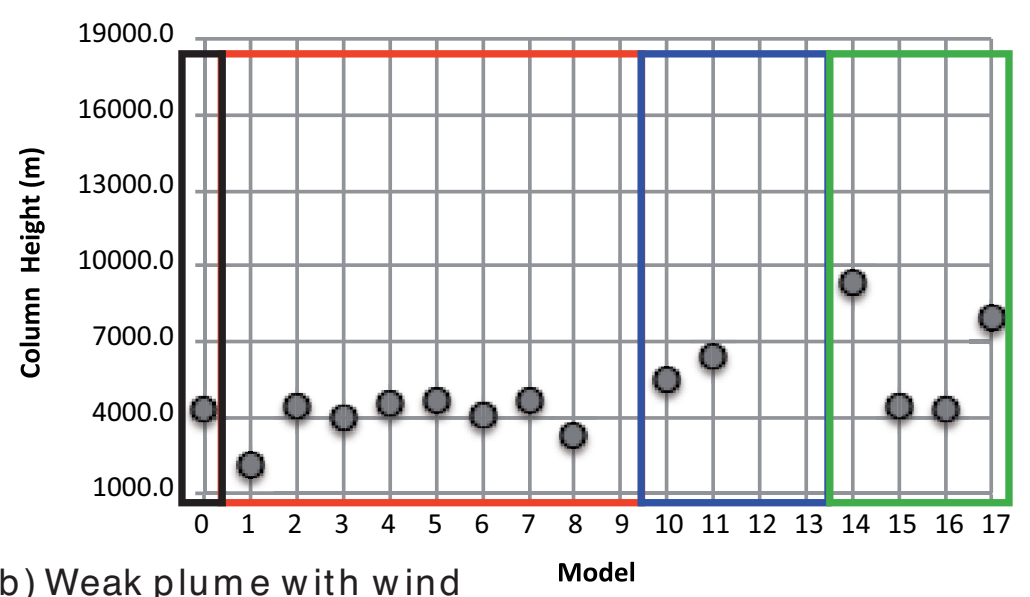

b) Weak plume with wind Model

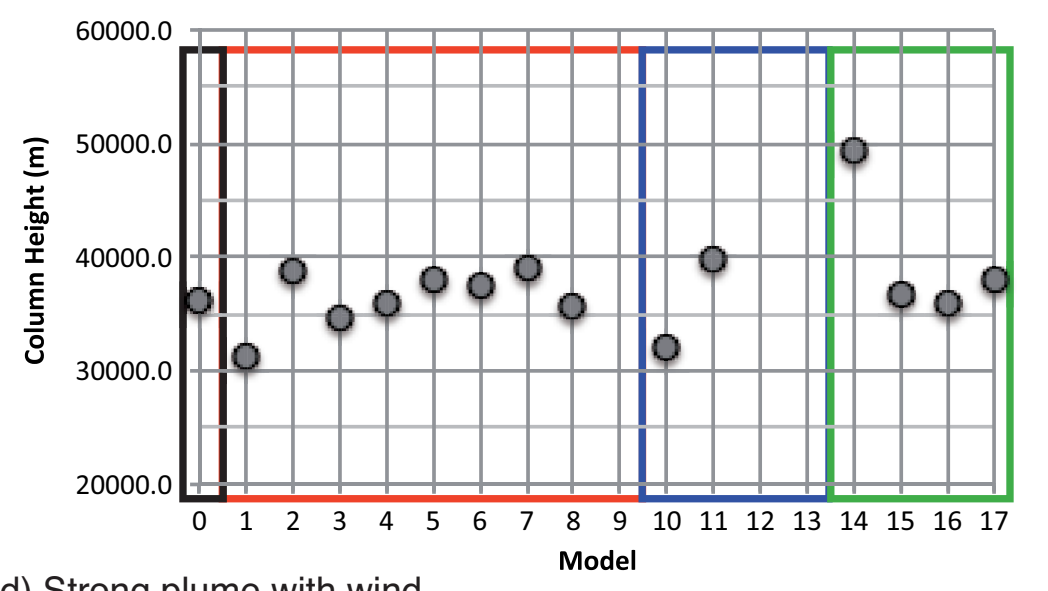

d) Strong plume with wind 
Weak plume (with wind): Fixed MFR

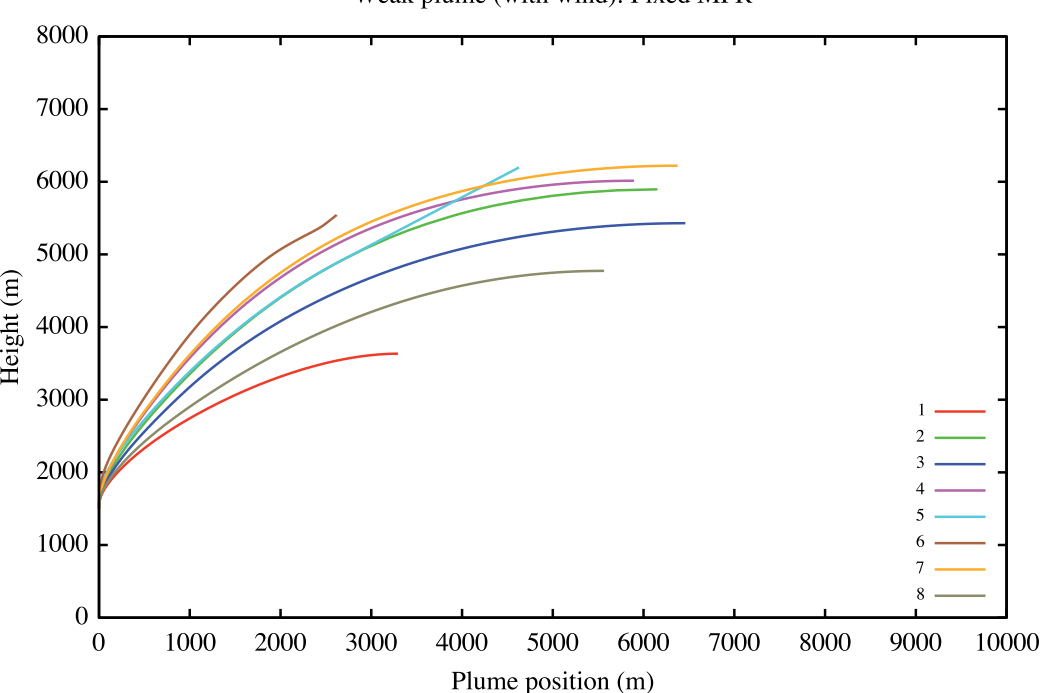

Weak plume (with wind): Fixed Column Height

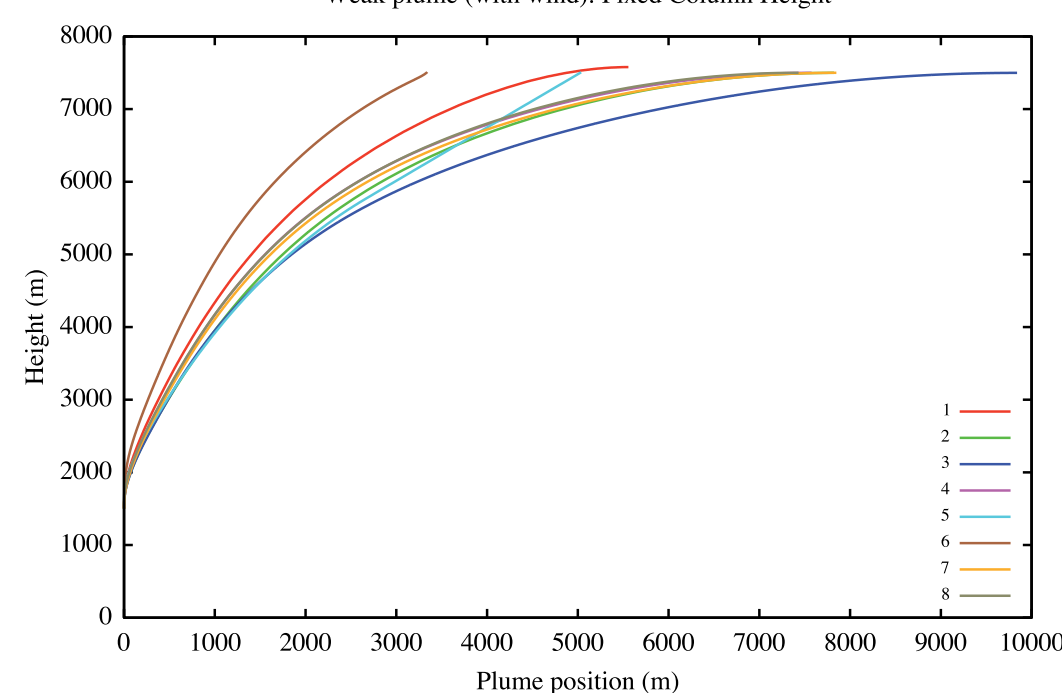


Weak plume (no wind): Fixed MER

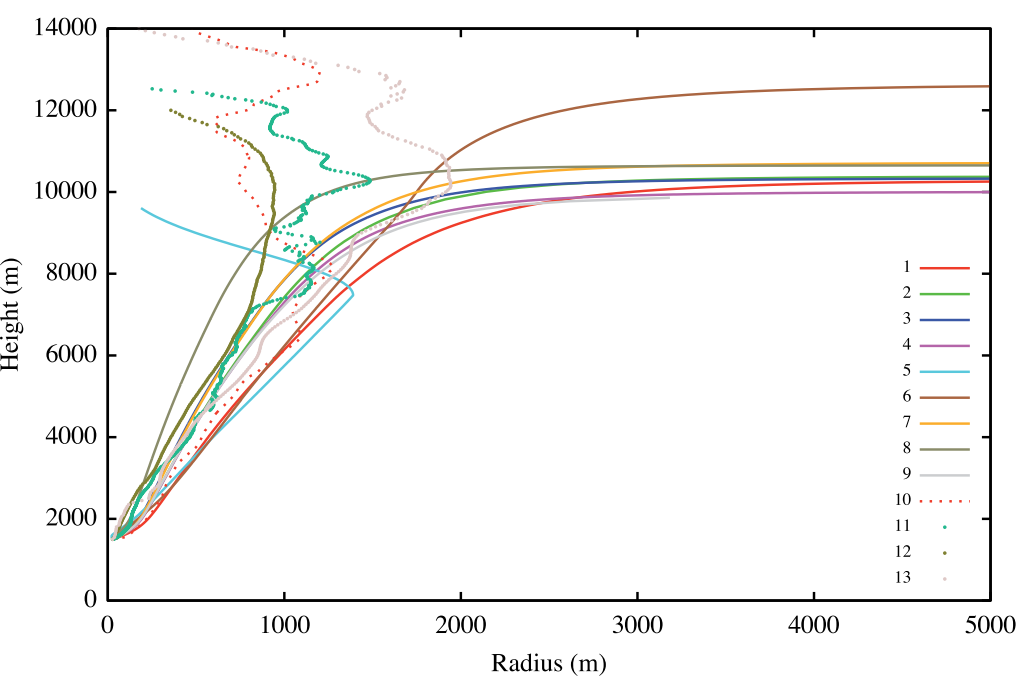

Weak plume (no wind): Fixed Column Height

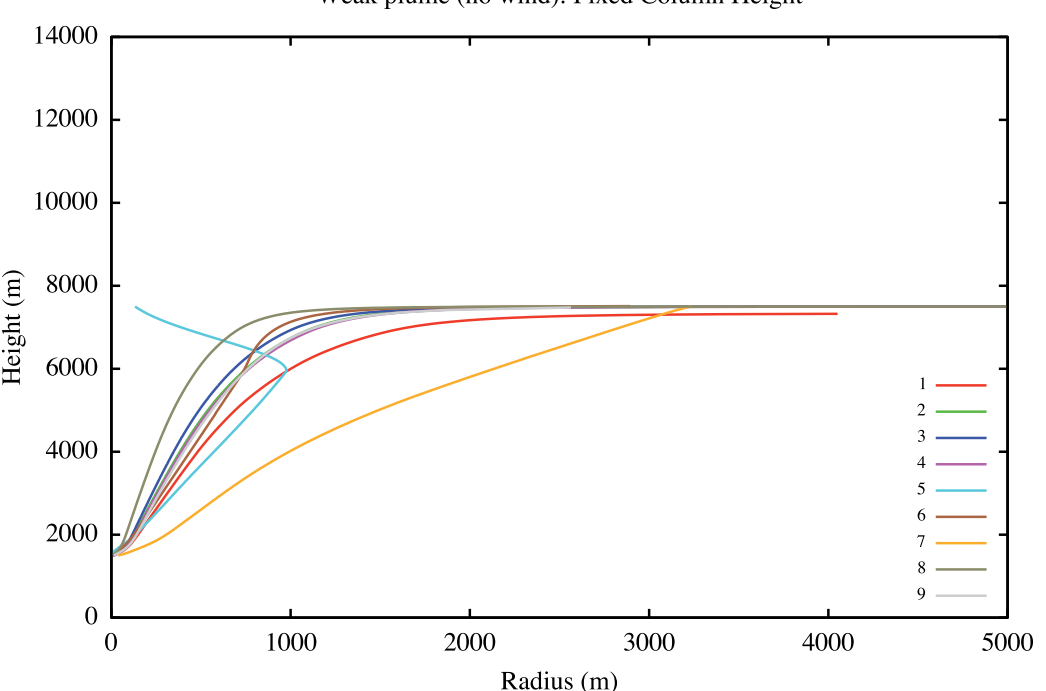

Weak plume (with wind): Fixed MER
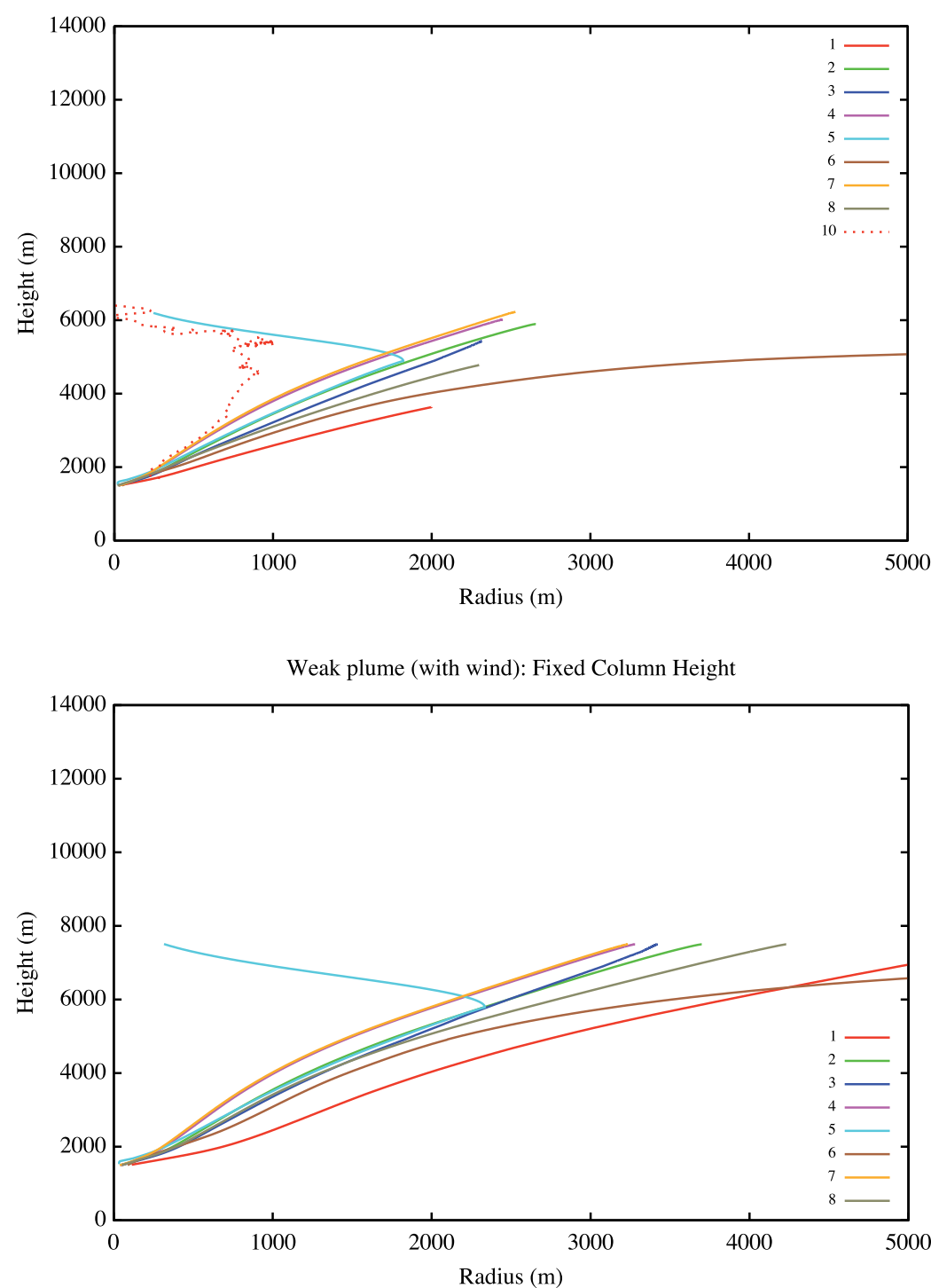
Weak plume (no wind): Fixed MER

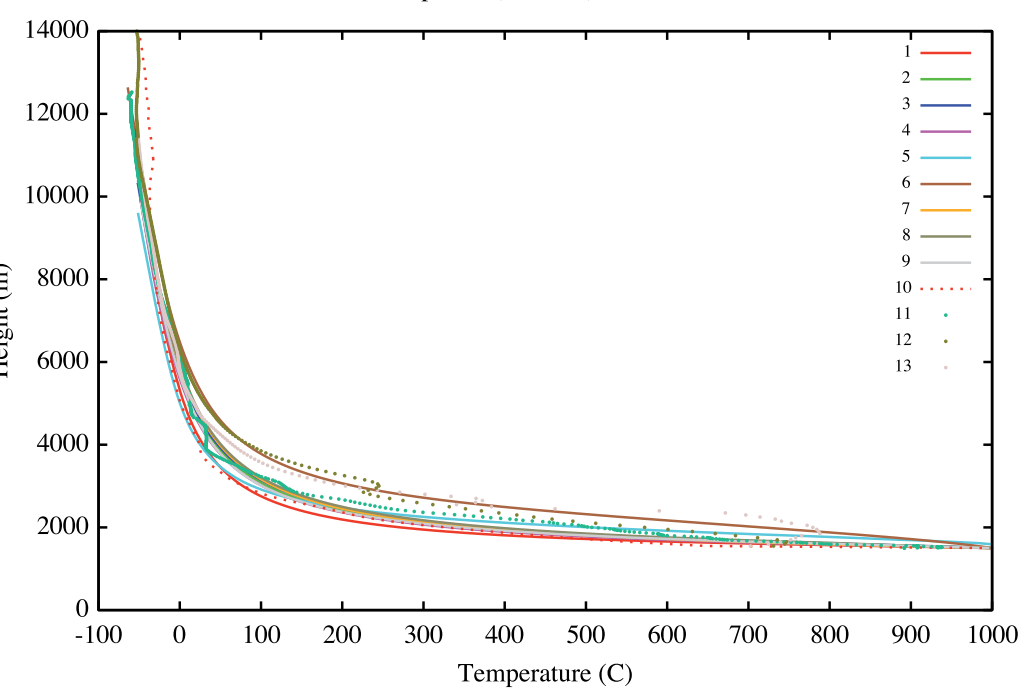

Weak plume (no wind): Fixed Column Height

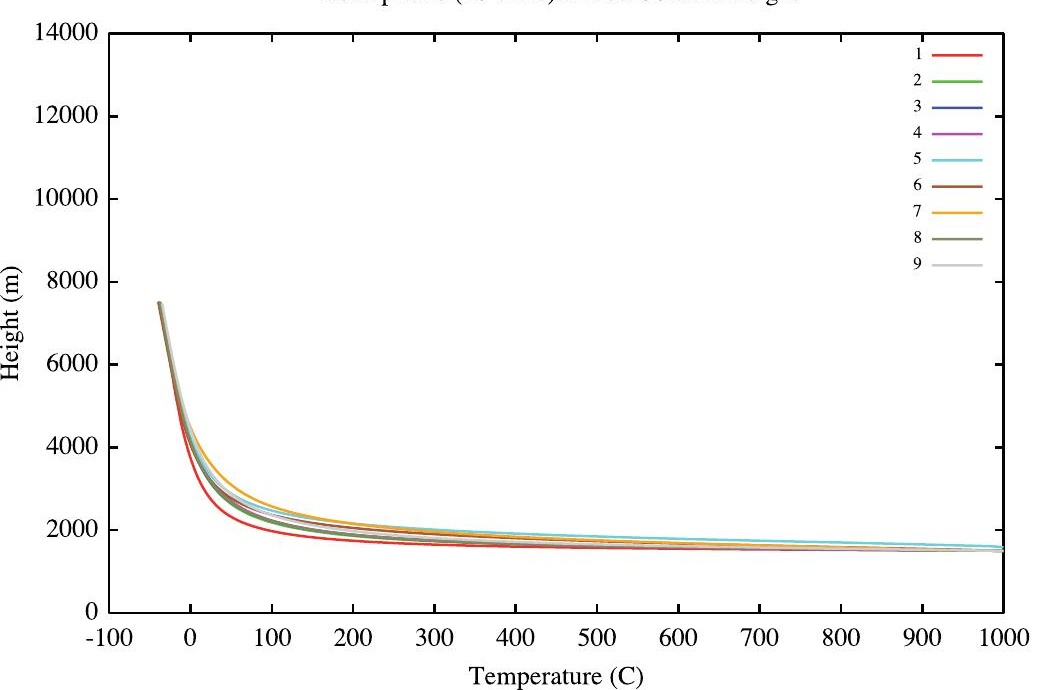

Weak plume (with wind): Fixed MER

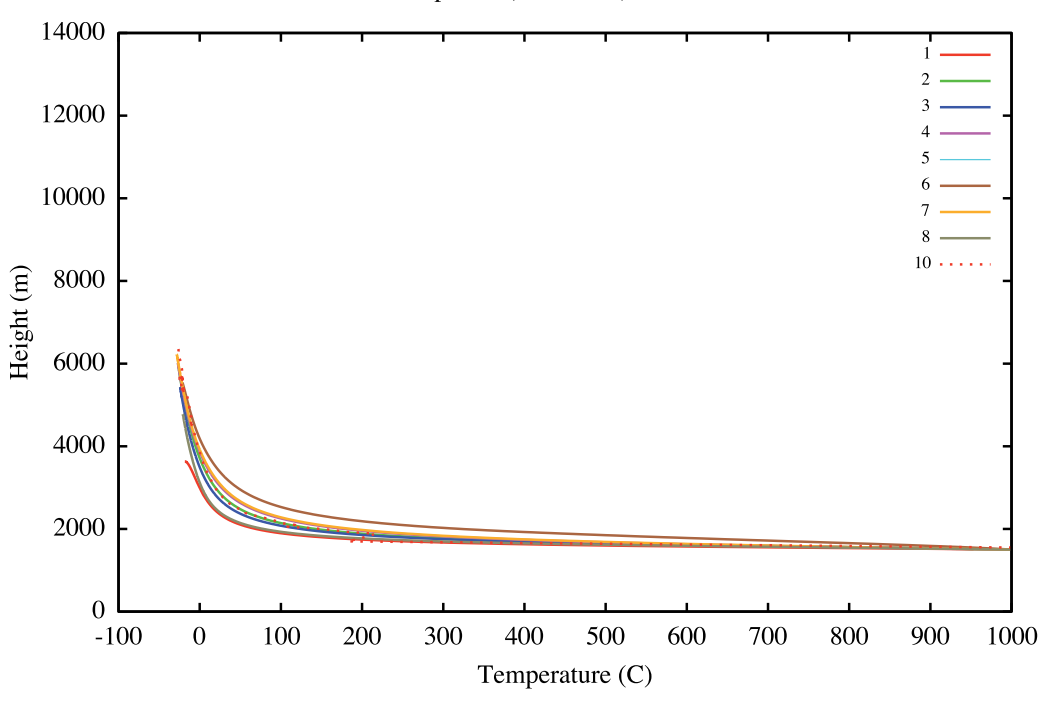

Weak plume (with wind): Fixed Column Height

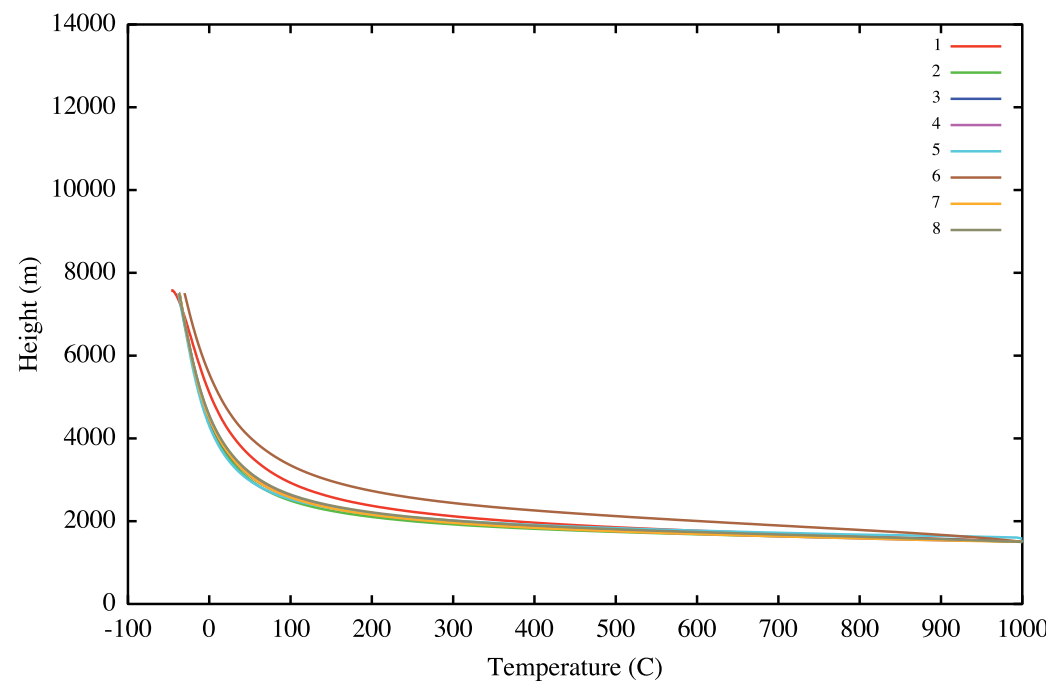


Weak plume (no wind): Fixed MER

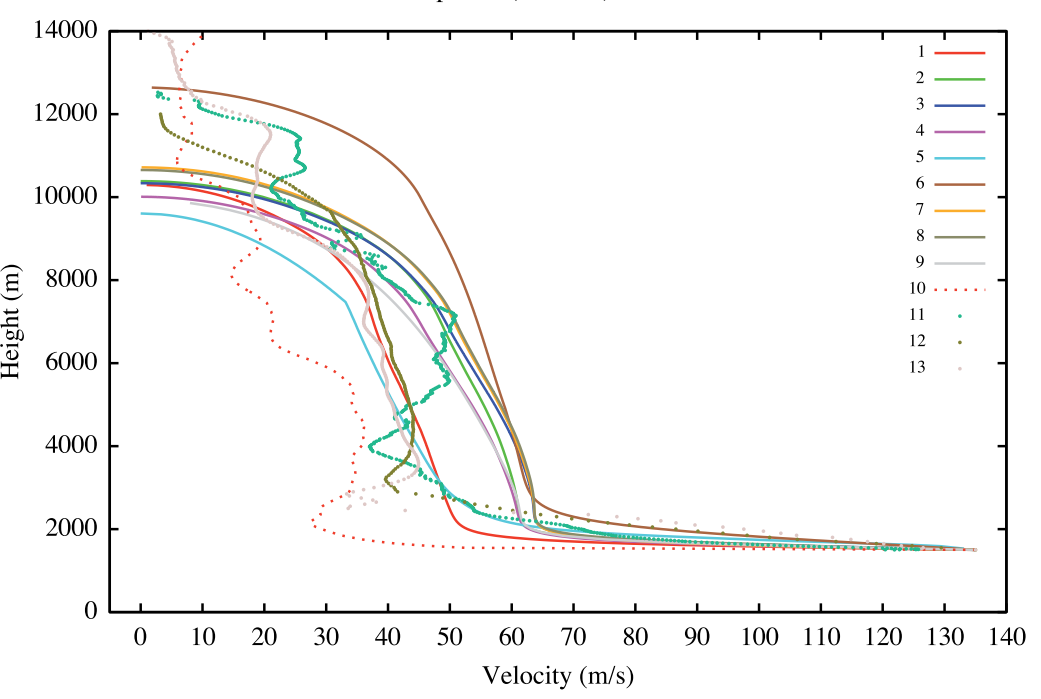

Weak plume (no wind): Fixed Column Height

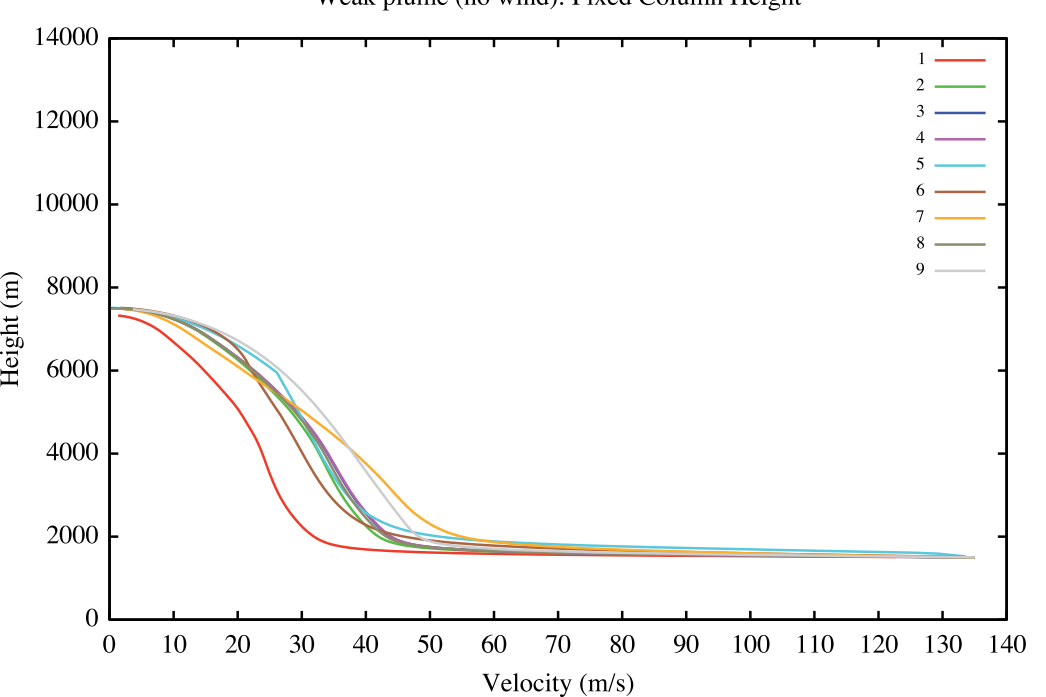

Weak plume (with wind): Fixed MER
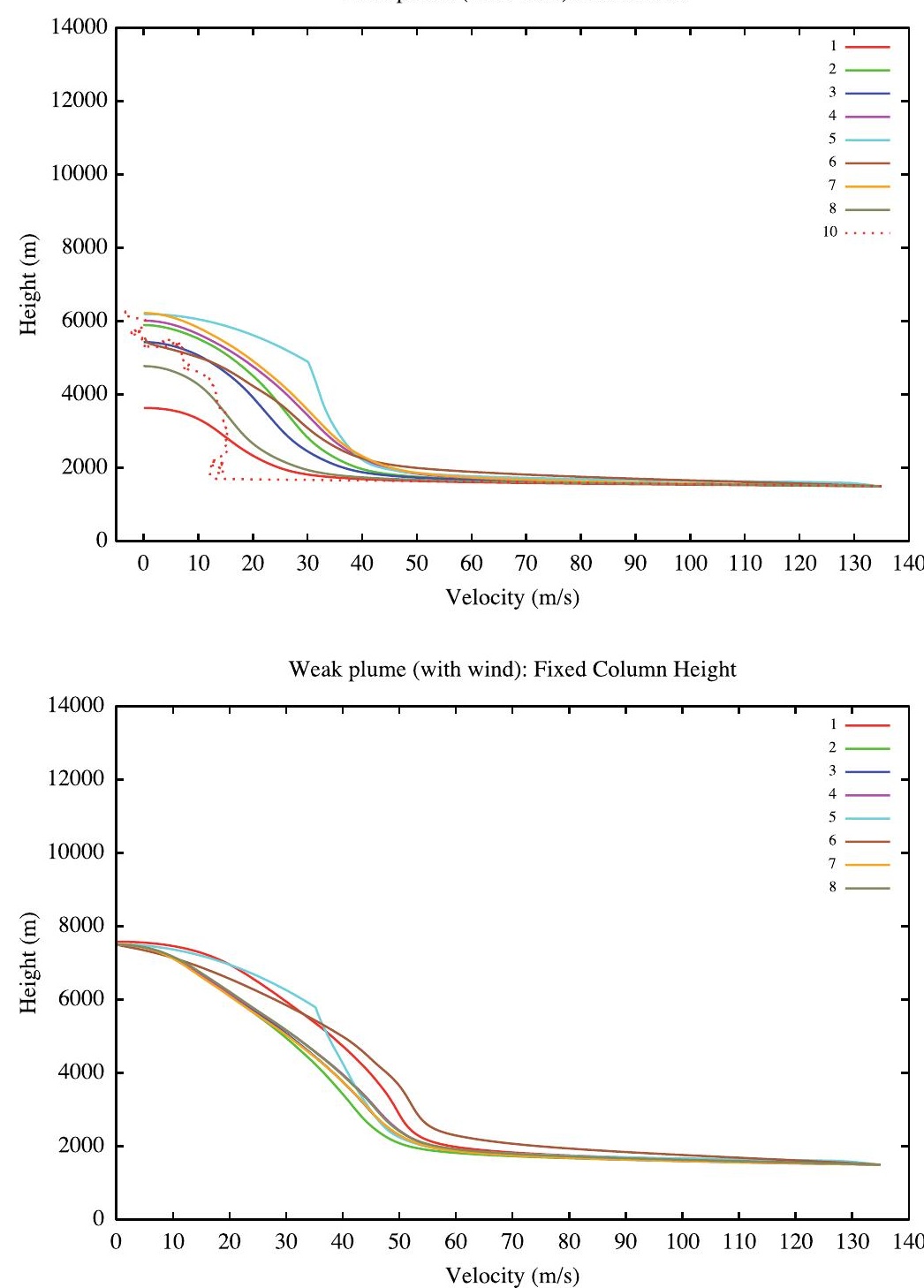
